\title{
ENSENAANZAS DEL CAMBIO FRACASADO: TRAYECTORIA Y ESTELA DE UNA PERÍFRASIS FUGAZ (INFINITIVO + TENER)*
}

\author{
Áluvaro S. Octavio de Toledo y Huerta \\ Ludwig-Maximilians-Universität München \\ Alvaro.Octavio@romanistik.uni-muenchen.de
}

Olvidaba / otra cosa: la música / frutal, el corazón / errante de los siglos, / suena para nosotros. / [...] Quiero / todo aquello que ha sido / el instante, [...] / lo que el tiempo / roe (no lo que el tiempo / purifica)

José Hierro, "Interior"

(Cuanto sé de mì), vv. 29-33, 47-53

Structures in which an infinitive precedes the auxiliary tener instantiate a very low-frequency, short-lived phenomenon in Spanish (15th-17th centuries). However, they are part of a broader constructional network that includes the so-called "analytical future" (cantarlo he) and, more generally, all periphrases exhibiting a

* Esta investigación ha sido posible gracias al apoyo de los proyectos españoles de I+D "Procesos de gramaticalización en la historia del español (ProGramEs) IV" (FFI2012-31427) y "Diccionario histórico de las perífrasis verbales del español: gramática, pragmática y discurso (GRADIA)” (FFI2013-43092-P). 
focus fronted infinitive. Hence, an in-depth study of this apparently marginal phenomenon can shed light on the reasons behind the simultaneous loss of all the aforementioned structures by 1660 . Furthermore, this single evolution exemplary shows how changes through syntactic extension come about and proceed, a process in which analogy seems to play a major role.

Key words: historical syntax (Spanish), infinitival periphrases, mesoclisis, focus fronting, syntactic extension, actualization, analogy.

Las estructuras con un infinitivo antepuesto al auxiliar tener constituyen un fenómeno de muy escasa frecuencia y corta vida en espańol (siglos XV-XVII). Se insertan, sin embargo, en un conjunto más amplio de construcciones que incluye al llamado "futuro analítico" (cantarlo he) y, en general, a las perífrasis en que el infinitivo asume la primera posición oracional merced a una focalización (fronting). Así, el estudio detallado de este fenómeno en apariencia marginal puede arrojar luz sobre el modo en que se produjo la pérdida simultánea de todas las estructuras mencionadas hacia 1660. Además, su historia muestra provechosamente el recorrido de un cambio por extensión sintáctica, proceso en el que parece desempeñar un papel crucial la analogía.

Palabras clave: historia del español, perífrasis de infinitivo, mesoclisis, adelantamiento de foco (fronting), extension sintáctica, actualización, analogía.

\section{UnOS (POCOS) DATOS, DOS HIPÓTESIS Y ALGUNA LAGUNA}

Fue el gran Wilhelm Meyer-Lübke, por cuanto se me alcanza, el primero en aludir a la existencia en español de una construcción "muy esporádica” en que un infinitivo se antepone directamente al auxiliar tener (1a). ${ }^{1}$

1 "Nur vereinzelt trifft man entsprechend sp. morir tenia" (Meyer-Lübke 1899: \$503, 540). El romanista suizo citaba por la Silva de romances viejos editada por Jacob Grimm (Viena, Jacobo Meyer, 1815), que sigue el Cancionero de romances de Amberes de 1555 (cf. Chico- 
El conocido romance en que la documentó (el del conde Alarcos) contiene un segundo ejemplo de esta construcción, esta vez con un clítico interpuesto entre auxiliado y auxiliar (1b). El mismo romance alberga, además, ejemplos de un esquema semejante a (1a), pero precedido de la preposición de, así como de otro esquema análogo al anterior con el auxiliar haber (1d). ${ }^{2}$

(1) a. No me pesa de mi muerte porque yo morir tenía, / mas pésame de mis hijos, que pierden mi compañía (Alarcos, 172-173)

b. Encomendaos a Dios, qu'esto hazerse tenía (Alarcos, 179)

c. De morir tiene, el buen conde, por salvar la honra mía (Alarcos, 94)

d. A morir habéis, condesa, enantes que venga el día (Alarcos, 167)

No muchos años después de Meyer-Lübke, Cirot (1911: 86) mencionaba un ejemplo de infinitivo + clítico + tener en el Guzmán de Alfarache (2a) que, según él, "est l'équivalent de ahorcaros hemos". Keniston

te 2000: 20-24). El texto figura igualmente, con idénticas lecturas, en la primera edición de ese cancionero (Amberes, Martín Nucio, s. a. [1547-1548]) y en el Cancionero de romances de Medina del Campo (Guillermo de Miles, 1550).

2 Los cancioneros citados en la nota anterior fueron realizados a partir de pliegos sueltos (cf. Higashi 2013): para el romance del conde Alarcos, los más tempranos (cf. Norton \& Wilson 1969: 13-14) son sevillanos, de Jacobo Cromberger (1511-1515 y ca. 1520, el segundo con atribución de la obra a un tal Pedro de Riaño) y Juan Valera (1516-1517), localización geográfica que, como veremos, puede ser de importancia. En el pliego suelto impreso por Jorge Coci en Zaragoza (1520), el ejemplo (1d) lee $A$ morir teneys y no, como la princeps sevillana, $A$ morir habéis (cf. Thomas 1927: 11/19 y García Lorenzo 1972:181); los Cancioneros imprimen De morir habéis, lo que pone de manifiesto el paralelismo entre los esquemas de (1c) y (1d). 
(1937: 466-467) localizó tres casos más con el clítico (2c) y otros tres sin él (2d), mientras Yllera (1980: 116-117) encuentra ejemplos de uno y otro esquema en Diego de San Pedro $(2 \mathrm{e})^{3}$ y García de Diego (1951: 194) cita un caso en el Quijote de 1615, datos que sugieren que el periodo de vigencia del fenómeno se corresponde en buena medida con los límites del español (pre)clásico, esto es, con el periodo que transcurre de 1475 a 1650, aproximadamente (cf. Girón 2004). ${ }^{4}$

(2) a. ¡Ea, ladrón, decí la verdad, que ahorcaros tenemos aquí si luego no lo dais! (Guzmán, I, 1, 7, 210)

b. no puedo más, seguirle tengo; somos de un mismo lugar (Quijote, II, 33, 906)

3 Además de un ejemplo anónimo en verso presente en el Cancionero de Gallardo, que recoge composiciones del Cuatrocientos pero se copió ya a mediados del siglo XVI: "que a quien no diçe verdad / deçille tienen que miente” (87, 69v, 4-5, apud Cancionero Virtual).

${ }^{4}$ Los últimos casos en prosa son de entre 1647 y 1650, y el último ejemplo de época áurea se da en el verso de una comedia calderoniana de 1665. Las pervivencias posteriores en prosa, escasísimas, se deben -más allá de la preservación del aforismo religioso (de) morir tenemosal arcaísmo deliberado que, en forma de imitación lingüística de rasgos tenidos por propios de la lengua antigua, conoció cierto éxito durante el siglo XIX (cf. Octavio de Toledo \& Pons 2009), o bien a la mímesis del español de los vascohablantes, asunto sobre el que volveremos más adelante. En verso se encuentran, entre el último tercio del XVIII y mediados del XIX, algunos ejemplos de la secuencia que + infinitivo + tener motivados sin duda por razones métricas y de rima: "pues sólo que añadir tengo / que en su casa cada una / mucho mejor estaremos" (Ramón de la Cruz, Las resultas de los saraos, 1764); "de los moros amparóse / y por los moros mantuvo / a Tarifa; mas tornose / la suerte: capitulose, / y Arias que entregarse tuvo" (Zorrilla, Granada, 1852). 
c. ¿Con quién habla? [...] Sabello tengo (Lozana, 42, 212-213) pues los pecados le mataron, aborrecellos tenemos (Ávila, Epistolario, 13, 179)

Ha dicho dos veces, estando retirada en su cámara: "no piensen que ha de pasar así, que yo casarme tengo" (Bernardino de Mendoza, Carta [a Felipe II sobre Isabel de Inglaterra], 14.5.1579)

d. conviene los corazones de aquellos que en arduo negocio proveer tienen estar desembargados de pasión (Lisandro y Roselia, I, 4, 146) No temas, Paulo, que llegar tienes a la presencia de César (Ambrosio de Morales, Discursos, III, 168r) ${ }^{6}$

¡Desta vez pagar tienes! (Guzmán, I, 3, 8, 450)

e. el día aplazado que los ensayos con obra esecutarse tenían (Arnalte, 699-700, 74)

E como yo supiese que Lucenda a la fiesta venir tenía, grandes alteraciones al triste coraçón mío sobrevinieron (Arnalte, 702-703, 74) ¿quién pensar pudiera que así las fuerças de mi propósito enflaquecer tenían? (Arnalte, 1446-1447, 124)

Además de su escasez, en que insisten todos los autores citados, y de su aparición únicamente en un arco cronológico muy ceñido, llama la atención en esta perífrasis el dominio (prácticamente, la exclusividad) del esquema con el auxiliar pospuesto al auxiliado. ${ }^{7}$ Este hecho subraya

5 En esta obra se encuentran, además, los ejemplos citados más adelante bajo (6b) y (6d).

6 Cito por la princeps (Córdoba, Gabriel Ramos Bejarano, 1586), donde he comprobado el dato.

7 En todos los ejemplos recogidos por Yllera "aparece el auxiliar pospuesto" (Yllera 
i24 Álvaro S. Octavio de Toledo y Huerta Clecm3(1)-2016

la semejanza del esquema infinitivo + tener (especialmente el que contiene un clítico) con el llamado "futuro (o condicional) analítico", cantarlo he / hia (en adelante, FCA), a cuya relativa abundancia hasta mediados del siglo XVII se contrapone la frecuencia históricamente muy baja del esquema haber + infinitivo (cf. ya Meyer-Lübke 1899: \$319, 337). De hecho, la mayoría de los especialistas supone que cantarlo tengo surgió por la notable expansión contextual de tener a costa de haber a lo largo del siglo XV, que en último término habría afectado también al FCA, entre otras perífrasis; ${ }^{8}$ no falta, sin embargo, quien prefiere poner de relieve

1980: 116), como en todos los de Keniston "tener follows the infinitive" (Keniston 1937: 467), salvo en el siguiente, si no es error de copia (pues Valdés usa generalmente tener de + infinitivo): "No fío tanto en mi memoria que piense me tengo acordar de todos" (Valdés, Lengua, 95v). Otro ejemplo que hemos localizado en el CORDE bien podría ser un caso de omisión haplológica de la preposición de ante un auxiliar comenzado por [d-]: "E non es maravilla si un omne tiene grant cargo en un regno del qual tiene dar cuenta a Dios" (Antón de Zorita, Árbol de batallas, 1440-1460).

8 " $[\mathrm{I}] \mathrm{t}$ is reasonable to conclude that tener did function as haber in analytic future / conditional constructions" (Anipa 2001: 158). "The identity in meaning of tener and haber during the sixtenth century made it easy for tener to replace haber in various auxiliary functions, both with a pure infinitive and with a preposition de" (Keniston 1937: 466). "Su creación [de cantarlo tengo] se explica por el auge que cobró tener en esos ańos [finales del XV] y durante el siglo XVI como sustituto de aver en sus diversos empleos. Apareció por analogía con aver e infinitivo, influenciada sin duda por la autonomía de los dos componentes del futuro y del condicional" (Yllera 1980: 116). Como puede verse en este último pasaje, la hipótesis de la sustitución léxica va de la mano de la concepción del futuro cantaré o el condicional cantaría también como secuencias analíticas, pues de lo contrario quedaría sin explicar la aparición de cantar \{tengo / tenia\}: "native speakers must have continued to conceive of the future as the infinitive + haber and therefore sometimes replaced haber with tener" (Anipa 2001: 158); cf. igualmente Anipa (2000). Para la sustitución de haber por tener en la historia del español, cf. sobre 
la afinidad de cantar(lo) tengo con $\{a /$ de\}cantar(lo) tengo (cf. 1c), perífrasis documentada en la misma época (e incluso, como hemos visto, en los mismos textos que cantar (lo tengo) y que puede explicarse fácilmente como la versión con anticipación del infinitivo del esquema tengo $\{$ a / de $\}$ cantar (lo). ${ }^{9}$

Surgen, así, dos posibles hipótesis evolutivas: una de mera sustitución léxica de haber por tener sobre el molde del FCA; y otra según la cual cantar (lo) tengo podría ser el resultado de una evolución propia (una gramaticalización, quizá) a partir de la perífrasis tener de + infinitivo (en la que, a su vez, tener venía reemplazando a haber desde fecha temprana: cf. Garachana 2011). Por lo demás, el estatuto diasistemático de los esquemas con infinitivo (+ clítico) + tener durante el tiempo en que estuvieron activos es asunto punto menos que desconocido: en vista de los ejemplos de (2), desde luego, no parece fácil defender, con Yllera (1980: 117), que "fue más una fórmula literaria que una construcción enraizada

todo Seifert (1930), Pountain (1985), Garachana (1997; 2011), Delport (2004), Hernández (2006), Del Barrio (en prensa). Para los FCA, construcción que ha merecido mucha atención crítica, cf. principalmente Rossi (1975), Company (1985; 2006), Company \& Medina (1999), Castillo (2002), Girón (2007), Bouzouita (2011; 2012), Octavio de Toledo (en prensa, a) y Batllori (en prensa).

9 Es la idea que parece latir tras este pasaje de la reseña crítica de Steven Dworkin al trabajo de Anipa (2001): "On the basis of a handful of examples [...], Anipa claims that he has identified for the first time the use of tener in analytic future constructions, parallel to the analytic constructions involving infinitive + aver. As the author himself recognizes, this construction denotes obligation (which implies futurity) and it arose through analogy with the periphrasis infinitive + aver. Nevertheless, it is going too far to analyze it as a future tense. This verbal periphrasis is documented in fifteenth century literary texts and existed alongside tener $a+$ infinitive and tener de + infinitive" (Dworkin 2004: 92). 
i 26 Álvaro S. Octavio de Toledo y Huerta CleCM3(1)-2016

en el habla viva”, es decir, que cantar(lo) tengo estuviera exclusivamente asociado al ámbito de la distancia comunicativa (en términos de Koch \& Oesterreicher 2011); su presencia en la Lozana andaluza, ${ }^{10}$ en cartas privadas o en entornos dialógicos del Quijote o el Guzmán sugiere, si acaso, lo contrario. A caracterizar sintácticamente los esquemas con tener y un infinitivo a lo largo de su historia y a afinar en lo posible su estatuto variativo dedicaremos las dos próxima secciones, en las que exponemos los datos que se derivan de un despojo exhaustivo de tales construcciones en el corpus CORDE. ${ }^{11}$ A partir del retrato que de ellos se desprenda trataremos de decantarnos, en la cuarta y última sección, por una de las dos hipótesis evolutivas esbozadas, o bien por una tercera que se antoje, quizá, aún más verosímil.

\section{Características Sintácticas de las SECUENCIAS CON INFINITIVO + TENER}

Se documenta desde los primeros monumentos literarios castellanos una construcción modal en que el infinitivo auxiliado, precedido del nexo característico de la perífrasis (preferentemente a en los primeros tiempos, 3a, y de más adelante, 3b-c: cf. Yllera 1980: 97-100), se antepone

10 Para esta obra como paradigma de la mímesis de lo oral, cf. Bustos (2001) y, particularmente sobre la cuestión de los futuros, Eberenz (1991).

11 He podido localizar en él 367 ejemplos (208 en prosa y 159 en verso), que constituyen el corpus de base de este estudio, aunque las cifras se referirán, salvo que se especifique lo contrario, tan solo a los ejemplos en prosa. Para el modo de recoger exhaustivamente secuencias de este tipo en el CORDE, cf. Octavio de Toledo (2002, en prensa, b). 
al verbo haber auxiliar: $\{a / d e\}$ cantar $(l o)$ he. En este esquema con adelantamiento de un sintagma entero (y no meramente de un núcleo), el infinitivo puede acompañarse de clíticos (3b) o no (3a). Se trata, en cualquier caso, de una secuencia de ínfima frecuencia, especialmente si se compara con el esquema cantarlo \{he / hia\}, lo que conduce a pensar que era este último, en realidad, el que actuaba la mayoría de las veces como esquema inverso ${ }^{12}$ de haber de + infinitivo con los dos tiempos de mayor uso (el presente y el imperfecto), al menos cuando en la construcción participaban los pronombres (Octavio de Toledo, en prensa, a). ${ }^{13}$

12 El esquema inverso de una perífrasis es aquel que muestra la anteposición del sintagma que contiene la forma no personal: así, cantar(lo) debo es, por ejemplo, el esquema inverso de las secuencias debo cantar, debo cantarlo, débolo cantar y lo debo cantar, en que el auxiliar precede al auxiliado según el orden tipológicamente esperable en una lengua VO como el espańol (cf. por ejemplo Greenberg 1963: 111; Dryer 1992).

13 En ausencia de los clíticos, la situación era necesariamente más compleja, pues cantar + he estaba muy avanzado en su gramaticalización como futuro (cantaré) ya en época protorromance (cf. por todos Valesio 1968; Nocentini 2001; Bourova \& Tasmowski 2007). La idea que recojo aquí, y sobre la que volveré algo más adelante (para los detalles, cf. Octavio de Toledo, en prensa, a), es que del mismo modo que he de cantar se impuso desde muy temprano a he cantar, al menos en Castilla (cf. Meyer-Lübke 1894: \$319: 337; Yllera 1980: 92-95), el esquema inverso de esta perífrasis se formó principalmente, en cambio, sin nexo entre auxiliado y auxiliar, es decir, en la forma que manifiesta el FCA cuando intervienen los clíticos. Concibo, de ese modo, la secuencia modal con haber y un infinitivo como una "perífrasis desgajada” por el efecto simultáneo de la formación del futuro sintético y de la tendencia a la generalización del nexo entre sus dos componentes: un único resto de la antigua perífrasis sin nexo, cantarlo he, se especializó de forma supletiva como esquema inverso de he $\{a /$ de $\}$ cantar + clítico para sus dos tiempos más característicos (presente e imperfecto), quizá precisamente porque los dos esquemas quedaban diferenciados de forma muy icónica por el carácter complementario de sus propiedades formales y distribucionales. Baste mencionar ahora, en todo 
i 28 Álvaro S. Octavio de Toledo y Huerta CleCM3(1)-2016

(3) a. si algunos de los reis mengua en algunas d'aquellas cosas que a complir an non son de culpar tanto como los otros omnes (GE1, XX, 46, 601)

b. De pasarse habrá ya esta importunidad (Celestina, 1, 44)

c. Lo quarto, deven criar las madres a sus fijos para tenerlos a su servicio más obligados; porque si los padres viven largos años, al fin de venir han a manos de sus hijos (Guevara, Reloj, II, 19, 513) porque la justicia, de trabajar ha el que la ha de administrar (Mejía, Silva, I, 32, 449)

El verbo tener accede a los entornos de (3) en el segundo cuarto del siglo XV, cuando el esquema tener de + infinitivo estaba ya firmemente asentado (Yllera 1980: 111-115; Garachana 2011; Garachana \& Rosemeyer 2011). Los ejemplos, muy contados en los dos primeros tercios del siglo (todos los casos en 4a), proliferan hacia los últimos años del Cuatrocientos, tanto en manuscritos como en impresos (4b), y la construcción

caso, que los ejemplos del tipo de (3a) que he podido localizar se encuentran en los primeros tiempos, al parecer, preferentemente insertos en oraciones subordinadas (una relativa, en 3a), entorno en que, como es sabido, no se localizan casos de FCA en los siglos XII-XIV (cf. sobre todo Castillo 2002; Company 2006; Bouzouita 2011). Por otro lado, el esquema inverso con presencia del nexo parece proporcionalmente más frecuente con tiempos distintos del presente o imperfecto, como el indefinido: "Lo que sant Millán dixo a veerlo ovieron" (Berceo, San Millán, 293a); "por ond a passar ovo" (Berceo, Santo Domingo, 220a); "non fue poridat lo que el obispo dixo del avenimiento de la hueste, pero a saber ovieron los altos ombres lo que Anfiarao dixiera" (GE2, Tebas, 286, 514); "quando vino la ora en que el sancto rey de finar ouo" (EE2, 1132, 772a). Ambos hechos, necesitados de ulterior comprobación, podrían venir en apoyo de la hipótesis recién esbozada. 
se hace presente en varias ocasiones en dos de las más influyentes obras del cambio de siglo, el Arnalte y Lucenda de Diego de San Pedro (cf. 2e) y el Amadis de Gaula impreso en Zaragoza por Jorge Coci en 1508 (4c). En este tiempo, la construcción, como puede verse, aflora tanto en el arranque de las oraciones principales como en diversas clases de subordinadas (relativas, sobre todo, pero también, en menor medida, completivas o prótasis condicionales), admite conjugarse tan solo en presente e imperfecto y carece de clíticos: hay que esperar al primer cuarto del Quinientos para encontrar ejemplos con pronombre (4d). ${ }^{14}$

(4) a. E veno adonjahu fijo de hagujd a bedsaba madre de salamon \& dixole sy es paz la tu venjda \& dixo paz es 9 E dixole de fablar tengo yo contigo \& dixole fabla (Biblia E3 [ms. de ca. 1425-1450], Re1 2:1314, fol. 191v-b, apud Biblia Medieval)

ca si de velar tenedes o penitencia de complir, otra noche vernedes mejor guarnido de armas e de gente (Ejemplos muy notables, ca. 1450) Estime el que amare que non solament e a su coamante de dar tyene, mas a otras çyento ha de contentar (Alfonso Martínez de Toledo, Corbacho, 1438 [ms. de 1466])

14 He aquí los otros dos casos tempranos que hemos localizado: "Nadie con mucho quereros / no cure de andar a caça / ni vos curés descenderos / que lo que cuesta dineros / de venderse tiene emplaça” (Per Álvarez de Ayllón, copla recogida en el Cancionero de obras de burlas provocantes a risa [Valencia, 1519, fol. 24r] y en el Cancionero de galanes, 1520); "Señora, pues esperança tengo que mi mal ha de bivir e siempre contigo leal compañía de detenerme tiene y pues mi daño á de crescer con la ansia de mis males, no sé qué podía perder que la vida” (Polindo, 1526). 
i 30 Álvaro S. Octavio de Toledo y Huerta ClECM3(1)-2016

b. pues que de fuerça aquellas nobles gentes y todos los que nascieron a morir tenian sin ser conoscidos en el mundo por los que oy son (Juan de Flores, Triunfo de amor, 1470-1492)

avré de ser perdonado si pareciere que siguo fablilla en la perfeción del triunfo que de escrivir tengo (Alonso de Palencia, Triunfo militar, 1459 [ed. de Sevilla,1490])

mas que me detengo en lo que escusar no se puede / a morir tiene este magnanimo rey (Gonzalo García de Santa María, trad. de fray Gauberto Fabricio de Vagad, Corónica de Aragón, 1499)

Señora, de hazer tengo vuestro mandado (Historia de la reina Sebilla, ca. 1500)

c. en él tengo yo aquella verdadera esperança que con razón de haver tengo (Amadis, 77, 1229)

pero dos cosas [...] hazen que mi propósito mudado sea. La una es querer vosotros, señores, a quien yo de servir tengo, ser en su ayuda (Amadis, 68, 1035)

Dueña, vayamos ante el Rey, y dándovos por quita, seré yo libre para me bolver donde de ir tengo (Amadis, 15, 388)

d. E su fición de manifestarse tenía, que la divina Magestad permite que las cosas mal hechas y peor pensadas no sean de luenga durada (trad. castellana de Tirante el Blanco, 1511)

Con similares características, pero aún más escasa, surge en paralelo (esto es, a partir de 1425) una construcción sin preposición encabezante (5a), que parece ser la versión con tener del siempre muy escaso esquema 
infinitivo + haber (5b). ${ }^{15}$ El primer caso que implica a un clítico tarda de nuevo más de medio siglo en aparecer $(5 \mathrm{c})$. La diferencia más signifi-

15 Para otros ejemplos medievales de infinitivo + haber, cf. Yllera (1980: 93-95). En los casos más tempranos de (5a) pudiera sospecharse influjo oriental (conocido en Villena y consustancial a un cancionero bilingüe, castellano y catalán, como PN4), por cuanto el esquema sin preposición pudo tener más presencia hacia el tercio este peninsular (y quizá también en el tercio oeste) que en la Castilla central. Así lo sugieren no solo los casos de (5b), adscribibles a esa zona, sino también la frecuencia no despreciable con que aflora la perífrasis haber + infinitivo conjugada en presente entre los corresponsales orientales de don Juan Manuel o Fernando el Católico, o su presencia en copias con clara impronta oriental como el manuscrito del Leomarte o el antiquior de la prosificación de la Teseida boccacciana: "e nos no avemos ninguna cosa otorgar sines voluntad e sabiduria vuestra” ("De Jaime II a su cuñado Don Dionis, sobre la paz de Castilla" [Colección diplomática de D. Juan Manuel], 1300); "assi auemos enuiar a la frontera los ditos ordenes de nuestra tierra" ("Respuesta de Alfonso IV de Aragón a la carta de Don Juan Manuel”, íbid., 1330); "e que os hauemos fauorescer e ayudar con nuestra casa e stado" ("Fernando al rey de Nápoles" [Documentos sobre relaciones internacionales de los Reyes Católicos], 1482); "non nos hauemos poner en semejante satisfaccion de interesses" ("Fernando a la reina de Nápoles", ibid., 1484); "E avras buscar otro amor de Nueuo \& otra fe que le des" (Leomarte, CCV, 114r); "que a las fembras en su verdadero hábito acostumbrado avemos honrar" (Teseida, I, 17, 83; así el ms. A, optimus y antiquior; el otro testimonio conocido, un descriptus de principios del XVI, trae avemos de honrar). La antelación cronológica de los esquemas orientales con tener sería también esperable si, como sugiere Del Barrio (en prensa), la sustitución de haber por tener fue más rápida cuanto más al este de la Península. No es sencillo, claro está, comprobar fehacientemente tales hipótesis, pues el esquema de (5b) solo puede distinguirse del futuro sintético en ciertos casos: con tiempos distintos del presente o el imperfecto (“Ora, pues así lo quieres, seguir avré tu consejo", Viraldo, I, 111; cf. también los ejemplos con el auxiliar en indefinido de la nota 13); con las formas largas del imperfecto (por oposición a las breves del tipo hía); con las formas largas habemos / habedes / habéis; cuando el auxiliar rige a dos o más auxiliados coordinados (operación que no está al alcance de los morfemas verbales del español: cf. el segundo caso de 5b); o con un infinitivo que cambia sistemáticamente su forma al integrarse como radical del futuro (cf. decir has frente a dirás). En todo caso, los ejemplos más tardíos de (5a) ya no pueden caracterizarse como orientales. 
I32 Álvaro S. Octavio de Toledo y Huerta CleCM3(1)-2016

cativa con la construcción de (4d) es que aquí todos los casos, sin excepción, se dan en subordinadas.

(5) a. El cual ovo tiempo de se tornar e librar de aquel peligro si a Casandra, su esposa, creer quisiera, que le declaró la muerte que padesçer tenía (Villena, Glosas a la Eneida [ca. 1428; ms. BNE MSS/10111, ca. 1450], 195r-a, apud BDH)

Pues morir tengo forçado / sin causa me matarás (Cancionero PN4 [ca. 1490], 24, 47v, vv. 6-7, apud Cancionero Virtual)

Un marinero le dixo dozientas millas de aquel puerto, mas por qué causa lo preguntava. "Por unos negocios que allí hazer tenía” -respondió don Polindo (Polindo, 1526)

b. por tal que nos mejor podiessemos acordar lo que fazer aviemos ("De Jaime II a Don Juan Manuel, excitándole a mantener en paz Castilla" [Colección diplomática de D. Juan Manuel], 1312)

todos sus vasallos a quien mandar y governar havemos (Amadis, 114, 1513)

c. Pues [...] el día aplazado en que los ensayos con obras esecutarse tenían fuese venido, al rey supliqué que [...] (Arnalte, 699-700, 74) pongan [los cardos] por liño en acequia larga por amor del regar donde regarse tienen (Gabriel Alonso de Herrera, Obra de agricultura, 1513)

Estas construcciones perifrásticas con tener, pues, tardaron en asociarse con los clíticos; pero, incluso cuando lo hicieron, no entraron de inmediato en competencia con el FCA, pues, amén de las diferencias 
morfológicas en el auxiliar de determinadas formas (todas las de imperfecto más la primera y segunda del plural en el presente), el FCA carecía de preposición nexual (a diferencia de 4d) y su nicho sintáctico característico eran las oraciones principales (a diferencia de 5c). En este sentido, los nuevos esquemas con tenery sin preposición reproducen la restricción que pesaba sobre los esquemas análogos con haber y un tiempo distinto del presente o el imperfecto (6a) o bien con una forma no acortada del imperfecto que, de ese modo, no coincide con la del "condicional analítico" (6b): estos solo figuran -siempre en muy escaso número- en subordinadas canónicas como las relativas y las prótasis condicionales durante la Edad Media y el primer siglo XVI. ${ }^{16}$ Solo después de 1525 encuentro ejemplos de esquemas con infinitivo + clítico + tener en oraciones principales: el más temprano que conozco es de la Lozana andaluza (6c, retomado de 2c). Simultáneamente comienzan a darse en las principales esquemas sin clíticos de infinitivo + haber (6d) e infinitivo + tener (6e).

(6) a. E nos, todo el conçejo de Segovia, confirmamos e otorgamos esta carta e esta donacion a vos, don Garci Martinez, e a los que heredarlo ovieren por vos depues de vuestros dias ("Confirmación de donación" Documentos de Alfonso X dirigidos a Castilla la Vieja, 1270) ${ }^{17}$

16 Solo conozco un caso de ambigüedad con un FCA (o, dicho de otro modo, un caso de FCA dentro de una subordinada canónica), en el siguiente ejemplo amadisiano: "Éste es un cavallero que demandarte ha el mal que me heziste" (Amadis, 128, 1657).

17 Un ejemplo muy similar se encuentra en otro documento alfonsí algo anterior dirigido al obispo Martín de León: "e mando que todos aquellos que y quisieren venir que vengan salvos e seguros con todas sus mercaduras; e, dando sus derechos o darlos ovieren, defiendo 
I34 Álvaro S. Octavio de Toledo y Huerta CleCM3(1)-2016

ca bien entendieron que sy guiar se ouiesen por este caballero, que los meteria en lugar do las manos ouiesen mester (Libro del caballero Zifar; cit. en Yllera 1980: 96) ${ }^{18}$

b. E bien les dio a entender Ebtor que por la sangre delos mayores dela hueste se auja a cobrar la çibdat / sy cobrarla aujan (Leomarte, 105, 67r) ¿A dó iré con el cuerpo? Pues el alma que regirle había le desmamparó (Lisandro y Roselia, III, 8; cit. en Keniston 1937: 461)

c. ¿Con quién habla? [...] Sabello tengo (Lozana, 42, 212-213)

d. ¿Así, doña puta, meter habías sin mi licencia en casa el paje del conde [...]? (Lisandro y Roselia, I, 4, 133)

e. Obedecer tenemos a los reyes, pero haziendo cosas de reyes (Bernardo Pérez de Chinchón, La lengua de Erasmo, 1533)

Con la emergencia del esquema con clítico(s) en el entorno propio del FCA, sin embargo, la construcción con tener varía de rumbo y emprende una rápida metamorfosis. En efecto, su asociación con los clíticos, esporádica hasta 1525 , se triplica hasta alcanzar porcentajes parejos a los del esquema sin clíticos ya a mediados de siglo. En paralelo, la construcción con preposición entra en declive, especialmente cuando intervienen los clíticos, de manera que puede percibirse una clara diferenciación formal entre dos

firmemientre que ninguno non sea osado delles façer fuerça nin tuerto" ("Carta Real” [1256], Documentos de Alfonso X dirigidos al Reino de León, apud CORDE).

18 La lectura es solo del ms. M, en el que se basa la ed. de Wagner que sigue Yllera; el ms. P, más tardío y con tendencia a la modernización lingüística (Lucía 2002), trae a guiar se oviessen, variante que demuestra, una vez más, hasta qué punto la perífrasis infinitivo + haber está emparentada con las modales con preposición. 
esquemas: el más tradicional, que carece de clíticos y se marca con la preposición, y el emergente, sin preposición y con algún clítico; este segundo se hará cada vez más presente, como muestra la Tabla 1 , y cuadruplica su peso respecto del periodo anterior entre 1525 y 1585, al tiempo que se hunden con estrépito las frecuencias del esquema contrario.

Tabla 1. Progresión de los esquemas con clíticos y sin preposición (prosa) ${ }^{19}$

\begin{tabular}{lrcccc}
\hline Periodo & +Clítico & -Clítico & +Prep & -Prep & $\begin{array}{c}\{-\mathrm{CL},+ \text { Prep }\} \text { vs. } \\
\text { \{+CL, -Prep }\}\end{array}$ \\
\hline $1425-1526$ & $4(17 \%)$ & $19(83 \%)$ & $16(70 \%)$ & $7(30 \%)$ & $14(61 \%)$ vs. $2(9 \%)$ \\
$1527-1584$ & $23(46 \%)$ & $27(54 \%)$ & $9(18 \%)$ & $41(82 \%)$ & $4(8 \%)$ vs. $18(36 \%)$ \\
$1585-1665$ & $62(46 \%)$ & $73(54 \%)$ & $9(7 \%)$ & $126(93 \%)$ & $5(4 \%)$ vs. $58(43 \%)$ \\
\hline
\end{tabular}

19 Los porcentajes de la Tabla 1 son siempre sobre el total de construcciones en prosa (23 para el primer periodo, 50 para el segundo y 135 para el tercero). La evolución señalada es también apreciable en el verso, aunque con proporciones distintas, que merecen algún comentario. Por un lado, son menores las cifras alcanzadas por la construcción con clítico: hasta 1526, hay 1 caso con clíticos por 7 sin ellos (12.5\% de presencia de clíticos); de 1527 a 1584, 8 con clíticos por 42 sin ellos (16\% de presencia de clíticos); y entre 1585 y 1665, 49 con clíticos por 52 sin ellos (47\% de presencia de clíticos). Es mayor, por contra, en los dos primeros periodos la tendencia a eliminar la preposición: en el primer periodo, 3 casos de 7 no la llevan (el 43\%); en el segundo son 45 los ejemplos sin preposición sobre un total de 50 (el 90\%); en el tercero, presentan elemento de enlace 14 casos de 101 (el 14\%), de los cuales tres se construyen ya con el nexo que: "Que hablaros tengo" (Lope, El alcalde mayor, 1604-1612). En definitiva, las secuencias en verso tienden a ser más breves que las de la prosa, pues en un número de ocasiones apreciablemente más alto carecen bien del clítico, bien de la preposición o de ambos (el esquema $\{-\mathrm{Cl}$, -Prep\}, por ejemplo, tiene una frecuencia global en verso de $87 / 159$ casos, o el $55 \%$, mientras en la prosa el peso de este mismo esquema desciende hasta el 44\%, o 92/208 casos). Es posible que los condicionantes métricos llevaran a preferir secuencias más cortas que pudieran tener, así, un encaje más sencillo en su correspondiente verso. 
i 36 Álvaro S. Octavio de Toledo y Huerta CleCM3(1)-2016

Por otro lado, desde las primeras apariciones del esquema con un infinitivo no precedido de preposición en oraciones principales (cf. 6c y 6e) la presencia del conjunto de esquemas en las oraciones subordinadas disminuye igualmente a gran velocidad, como muestra la Tabla 2: de un claro predominio de la inserción en subordinadas hasta 1526 (16 casos de 23 o un $70 \%$ ) se pasa a una participación muy pequeña en estas oraciones durante el periodo siguiente $(7 / 51,14 \%)$ y a un porcentaje despreciable (inferior al 1\%) desde $1586 .{ }^{20}$ Especialmente marcado es el aumento de la presencia en oraciones principales cuando intervienen los clíticos: después de 1526 no habrá ya ni un solo ejemplo de esquema con clíticos dentro de una subordinada, tendencia que de nuevo apunta hacia una rápida igualación distribucional con los FCA. De hecho, la proporción

${ }^{20}$ La Tabla 2 distingue los contextos habitualmente considerados relevantes para la aparición de los FCA y de la enclisis de las formas pronominales con un verbo finito (cf. por ejemplo la nómina de contextos en Nieuwenhuijsen 2006). Solo se tienen en cuenta los casos en prosa, pues el verso puede suscitar con frecuencia un orden de palabras poco habitual. Hacia la izquierda de la tabla figuran los contextos de proclisis generalizada y hacia la derecha los de enclisis generalizada, con los entornos alternantes en el centro: $\mathrm{R} / \mathrm{Cn}=$ esquema dentro de una oración relativa / condicional; $\mathrm{Cp} / \mathrm{Cs}=$ esquema dentro de una oración completiva / causal "fuerte"; Cs' = esquema inmediatamente tras un nexo causal "débil" o de justificación enunciativa (generalmente $\mathrm{ca} /$ que: cf. Iglesias 2000) que no inhibe necesariamente la enclisis; Cs' $+\mathrm{SX}=$ como el caso anterior, pero con uno o varios sintagmas interpuestos entre el elemento causal "débil" y la perífrasis; Conx _ = esquema tras un conector o marcador discursivo inicial; $\mathrm{Adv}_{-}=$esquema tras un adjunto adverbial (adverbio o locución) inicial; $\mathrm{Sj}_{-}=$esquema en oración principal, inmediatamente tras un $\mathrm{SN}$ que funciona como sujeto (pronombre o $\mathrm{SN}$ topicalizable); Sub_ = esquema inmediatamente tras la pausa de una oración subordinada precedente; peroly $y_{-}$esquema inmediatamente tras nexo coordinante adversativo o copulativo; Voc/\#_= esquema tras un vocativo inicial o en el arranque absoluto del periodo. 
de casos que figuran en entornos que favorecen claramente la presencia de los FCA (los de las tres casillas más a la derecha en la Tabla 2) es tan solo del 17\% (4/23) para el periodo inicial, pero asciende ya al $47 \%$ (24/51) en los ańos centrales del siglo XVI y alcanza el 72\% (96/134) en el tramo final de la existencia de estos esquemas.

Tabla 2. Distribución de los esquemas (de) + INF $(+\mathrm{Cl})+$ tener según el entorno sintáctico

\begin{tabular}{|c|c|c|c|c|c|c|c|c|c|c|}
\hline Periodo & $\mathrm{R} / \mathrm{CN}_{\mathrm{N}}$ & $\mathrm{Cp} / \mathrm{Cs}$ & $\mathrm{Cs}^{\prime}+\mathrm{SX}$ & Cs' & Conx_ & $\mathrm{ADV}_{-}$ & $S_{J_{-}}$ & $\mathrm{SuB}_{-}$ & PERO/Y & Voc/\#_ \\
\hline $1425-1526$ & $9 / 2$ & $4 / 1$ & 2 & --- & -- & -- & 1 & -- & --- & $1 / 3$ \\
\hline $1527-1585$ & $6 / 1$ & --- & 3 & 12 & 1 & 1 & 3 & 4 & $1 / 2$ & $1 / 16$ \\
\hline $1586-1660$ & --- & $1 / 0$ & 5 & 12 & 8 & 4 & 8 & 32 & $0 / 15$ & $1 / 48$ \\
\hline Total & $15 / 3$ & $5 / 1$ & 10 & 24 & 9 & 5 & 12 & 36 & $1 / 17$ & $3 / 67$ \\
\hline
\end{tabular}

Los procesos recién reseñados van de la mano de un importante aumento en las frecuencias globales de las secuencias $(d e)+\mathrm{INF}(+\mathrm{Cl})$ + tener. Como muestra la Figura $1,{ }^{21}$ los tres fenómenos comentados (aumento de la proporción de esquemas con clítico, arrinconamiento

${ }^{21}$ La Figura1 ofrece cifras porcentuales correspondientes a cada valor parametrizado (presencia de al menos un clítico, presencia de la preposición ante el infinitivo, presencia en oraciones principales) para cada uno de los periodos cronológicos que se distinguen. La línea de mayor grosor en la zona inferior de la figura es una curva de frecuencias relativas del conjunto de esquemas, esto es, representa el porcentaje de casos sobre el total que se concentra en cada tramo temporal. Solo se han considerado, una vez más, los ejemplos localizados en la prosa. 
i 38 Álvaro S. Octavio de Toledo y Huerta CleCM3(1)-2016

de los esquemas sin preposición y abandono de las oraciones subordinadas en favor de las principales) crecen con especial ímpetu en el segundo tercio del siglo XVI, al tiempo que la frecuencia global de la construcción también experimenta un notable avance. ${ }^{22}$ Resulta evidente, pues, que la tendencia a la consolidación, entre 1525 y 1560, de un esquema infinitivo + clítico + tener (cantarlo tengo) localizado casi exclusivamente en oraciones principales, esto es, de una construcción con tener enteramente correspondiente al FCA cantarlo he, fue precisamente el hecho que permitió su despegue cuantitativo. Las construcciones con tener y un infinitivo, pues, tuvieron éxito en la medida en que tendieron a converger, a partir del segundo cuarto del siglo XVI, con el FCA. Importa, con todo, hacer aquí dos precisiones adicionales, cuya relevancia trataremos de mostrar más adelante: si la pérdida de la preposición y el desalojo de los entornos subordinados se producen en un solo impulso de avance rapidísimo para alcanzar prontamente cotas muy altas que continuarán

22 Para facilitar la comparación con los datos ofrecidos en las Tablas 1-2, dejamos aquí apuntado que la progresión de la construcción es prácticamente aritmética a lo largo de los tres periodos que estas distinguen: entre 1425 y 1485 la frecuencia se duplica respecto del tramo anterior, para duplicarse de nuevo en el último tramo (1586-1660). La Figura 1 permite apreciar con mayor detalle que los incrementos se concentran en el segundo cuarto del siglo XVI y el primer tercio del XVII. El cálculo de frecuencias relativas (porcentajes sobre el total para cada periodo) evita la deformación de los datos que pudiera producirse por las diferencias de volumen textual entre los diferentes periodos dentro del CORDE. El cálculo de frecuencias ponderadas (ajustadas en función de un factor multiplicador que tenga en cuenta dichas diferencias de volumen) arrojaría los mismos resultados, con unos 20 ejemplos para el primer periodo, unos 48 para el segundo y unos 99 para el tercero. Para estos métodos de cálculo y el tratamiento cuantitativo de los datos del CORDE, cf. Octavio de Toledo (en prensa, b). 
creciendo, ya más lentamente, hasta el final, el avance de los esquemas con clíticos frente a los que no los presentan, en cambio, venía dándose con vigor ya desde antes, en el tránsito del siglo XV al XVI, y se estancará a mediados del Quinientos para decrecer incluso en el ultimo tramo de vida de estos esquemas.

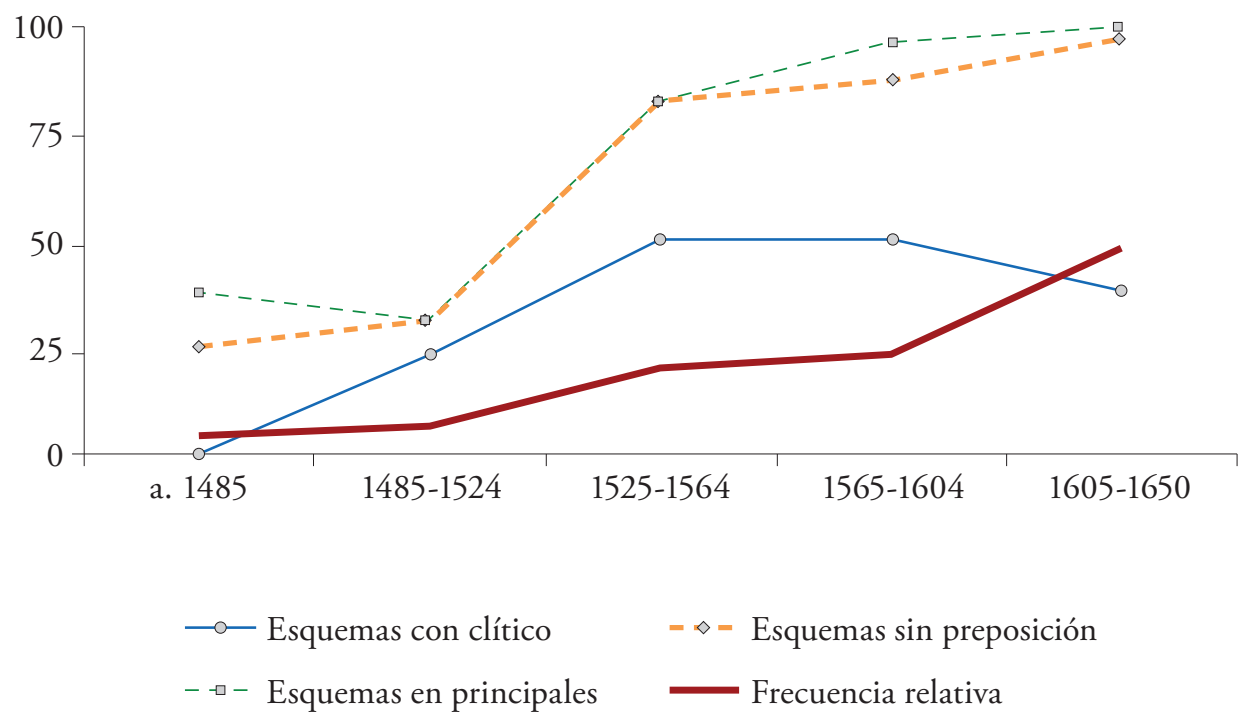

Figura 1. Valores porcentuales (para cada periodo) de varios parámetros combinados y frecuencia global relativa para los esquemas con infinitivo antepuesto a tener

Mencionaremos, finalmente, otros dos rasgos (morfo)sintácticos compartidos por todas las secuencias con un infinitivo antepuesto al auxiliar tener. De un lado, estos esquemas nunca aparecen negados, esto es, se muestran, desde sus primeras documentaciones hasta las últimas, tan 
i 40 Álvaro S. Octavio de Toledo y Huerta ClECM3(1)-2016

refractarios a la negación como lo son, conocidamente, los FCA. De otra parte, todos los ejemplos recuperados, tanto en prosa como en verso, manifiestan únicamente el empleo de dos tiempos verbales, el presente y el imperfecto del indicativo. Mientras que el primero de estos rasgos (la resistencia a la negación) bien puede considerarse heredado del modelo de origen (las perífrasis con un infinitivo antepuesto a haber, que, por lo que sabemos, tampoco aparecen nunca en entornos negativos), la segunda característica no puede hacerse remontar a esas construcciones (cf. ejemplos con diversos tiempos en 3b, 6a y la nota 13), sino que debe entenderse más bien en relación con la perífrasis hacia la que en último término acaba convergiendo, ya sea esta el FCA u otra de propiedades semejantes. Nos contentamos por el momento con mencionar aquí estos aspectos, que retomaremos igualmente en el apartado final.

\section{Estatuto VARIATIVO DE LAS SECUENCIAS CON INFINITIVO + TENER}

Durante el siglo XV, los primeros -y aún muy escasos- ejemplos de secuencias con un infinitivo antepuesto a tener afloran en textos que, como es característico de esa centuria, presentan un alto grado de elaboración intensiva en la dirección de la máxima distancia comunicativa (cf. Pons 2006). En la sintaxis, la gestación de la lengua elaborada cuatrocentista se manifiesta principalmente en la adopción de rasgos tenidos entonces por propios de la escrituralidad latina y adoptados ya directamente de esta, ya de la prosa toscana latinizante del Trecento, transmitida en no pocas ocasiones a través del oriente peninsular (cf. Pons, en prensa). Uno de esos rasgos es sin duda la colocación del verbo finito al fin 
de la oración, y en particular de las subordinadas canónicas. ${ }^{23}$ Esa tendencia estilística pudo favorecer la inserción en la escritura de secuencias con el auxiliado antepuesto al auxiliar, si bien preferentemente en subordinadas y en textos altamente elaborados: de ahí, posiblemente, la impresión de que esta perífrasis constituye (o al menos forma parte de) una "fórmula literaria", en términos de Yllera (1980: 117).

Merece la pena, sin embargo, detenerse en la distribución textual de estas secuencias durante los siglos XVI y XVII, es decir, en el tiempo de su mayor difusión. Para ello, he creído oportuno distinguir diez grupos textuales, reunidos en tres grandes bloques: tradiciones discursivas 24 narrativas que ya presentaban la construcción $(a / d e+)$ infinitivo (+ clítico) + tener en el siglo XV (bloque I, grupos a-c); tradiciones discursivas no ficcionales (bloque II, grupos a-c); ${ }^{25}$ y nuevas tradiciones ficcionales características del periodo áureo (bloque III, grupos a-b), además de la prosa efímera y las colecciones de refranes (bloque III, grupos $\mathrm{c}-\mathrm{d}$ ), según se detalla a continuación:

23 En las relativas, especialmente, el orden que XV (donde X es cualquier constituyente o serie de constituyentes y $\mathrm{V}$ es el verbo finito) es muy dominante en el Cuatrocientos y mantiene gran vigor aún a lo largo del español clásico (Del Barrio 2010).

24 Empleo aquí la noción de tradición discursiva en el sentido de Kabatek (2005; 2007; 2011), si bien en este caso el empleo es perfectamente compatible con una concepción de las tradiciones discursivas más orientada a la correspondencia con las taxonomías de género, tipo y modalidad textual (cf. López Serena 2011).

25 También la prosa erudita presenta algún caso de infinitivo antepuesto a tener en el siglo $\mathrm{XV}$, al menos si se considera dentro de este grupo (y no de la historiografía, según en buena medida se concebía en su tiempo) la labor de traducción y glosa de la Eneida por Villena. 
I42 Álvaro S. Octavio de Toledo y Huerta ClECM3(1)-2016

Ia. Libros de caballerías y ficción caballeresca

Ib. Novelas sentimentales (incluye las pastoriles, bizantinas y cortesanas)

Ic. Historiografía (crónicas y relaciones)

IIa. Prosa erudita, doctrinal, filosófica, religiosa y moral

IIb. Textos técnicos (de medicina, arquitectura, arte militar, náutica, etc.)

IIc. Textos jurídicos (ordenamientos y comentarios, ordenanzas y arbitrios, documentos legales públicos o privados, correspondencia oficial)

IIIa. Otras obras de ficción (diálogo de ficción, picaresca, novela alegórica, narración breve: novella y cuento, etc.)

IIIb. Teatro en prosa (incluye la Celestina y otras obras celestinescas)

IIIc. Prosa de circunstancias (relaciones de actos ceremoniales, encomios, oratoria sagrada o profana, prosa periódica, etc.)

IIId. Paremiología

Esta agrupación (tan arbitraria, por lo demás, como cualquier otra) se justifica principalmente por su rendimiento a la hora de dar cuenta de la distribución textual de otras perífrasis con el infinitivo antepuesto a un verbo de contenido modal y uno o más clíticos intermedios (lo que en adelante denominaré “tipo ICVm”). Como se aprecia en la Tabla 3, las perífrasis de esta índole con poder se concentran en masa en los textos narrativos que prolongan los usos escriturales del Cuatrocientos, lo que sugiere una mayor vinculación con los moldes sintácticos de la lengua elaborada, como el orden con verbo al final en entornos de subordinación; las perífrasis con deber, como era de esperar, tienen mucha más presencia que las demás en textos con un marcado carácter instruccional, como los jurídicos y técnicos; y los esquemas con querer son más abundantes que el resto en obras 
con un destacado componente monológico (las primeras novelas sentimentales, por ejemplo) o dialógico (grupos IIIa-b), pues suele ser la primera persona la preferida para expresar el deseo o voluntad.

Tabla 3. Frecuencias relativas de aparición del tipo ICVm con cada predicado modal en los tres grandes bloques textuales. Siglo XVI (datos del CORDE)

\begin{tabular}{lccc}
\hline & PoDer & QUERER & DEBER \\
\hline Grupo I & $\mathbf{8 2 \% ( 4 8 9 / 5 9 6 )}$ & $66 \%(189 / 287)$ & $52 \%(45 / 87)$ \\
Grupo II & $15 \%(90 / 596)$ & $12 \%(35 / 287)$ & $\mathbf{4 4 \% ( 3 8 / 8 7 )}$ \\
Grupo III & $3 \%(17 / 596)$ & $\mathbf{2 2} \%(63 / 287)$ & $4 \%(4 / 87)$ \\
\hline
\end{tabular}

Si atendemos a la distribución textual de los esquemas con anteposición del infinitivo a tener durante el Siglo de Oro que muestra la Tabla $4,{ }^{26}$ se observa fácilmente que el bloque I apenas da cuenta de un $17 \%$ de los ejemplos, y ello solo gracias a que entre los textos historiográficos se incluyen algunas relaciones particulares (de Alonso Borregán, Pedro Pizarro o la anónima de las Cerimonias y rictos... de los indios... de Mechuacán) que en absoluto pueden identificarse con la búsqueda deliberada de la distancia comunicativa y que aportan la mitad -es decir, ocho- de los ejemplos del grupo Ic; ${ }^{27}$ por otra parte, el grupo IIa es el

26 La Tabla 4 ofrece en su última fila las proporciones de uso que representa cada grupo textual sobre el total, destacando en negrita las dos cifras más altas.

27 Borregán y Pizarro, por ejemplo, forman parte del grupo de historiadores que Stoll (2014) denomina "semicultos". 
I 44 Álvaro S. Octavio de Toledo y Huerta ClECM3(1)-2016

más numeroso, alimentado sobre todo por las obras de devoción, enseñanza cristiana e introspección ascética, ${ }^{28}$ entre las que destacan las del reformador trinitario Juan Bautista de la Concepción, quien reúne por sí solo, con 66 casos (30 con clítico y 36 sin él), un 35\% de los ejemplos áureos; pero, aun prescindiendo por entero de su aportación, el grupo IIa seguiría siendo el más numeroso junto al IIIa, en el que el protagonismo corresponde claramente a la literatura picaresca del Seiscientos (un total de 26 casos, de los cuales ocho en el Guzmán, otros ocho en El guitón Onofre y aún ocho más en el Alonso, mozo de muchos amos), precedida en el XVI por algunos diálogos de ficción (los Coloquios de Palatino y Pinciano o el Capón, ambos con un caso); no son tampoco escasos los ejemplos de los grupos IIIb-d, igualmente alejados de la estilización propia de la prosa culta más elaborada. Las subordinadas se concentran particularmente en el bloque I (5/12 casos) ${ }^{29} \mathrm{y}$, dentro de este, principalmente en la ficción caballeresca. Esta distribución recuerda en buena medida, pues, la que puede establecerse para el tipo ICVm con deber, el predicado de entre los analizados que resulta más afín a tener, en vir-

28 De Francisco de Osuna a Juan de los Ángeles pasando por Luis de León, por ejemplo: "El un rico y el otro gastar tienen: el gasto manifiesta quién es cada uno (Francisco de Osuna, Quinta parte del Abecedario espiritual, 1540); "Y dice el que ama: grave cosa es esta; y dice el corazón: de llevarla tenemos" (Fray Luis de León, Exposición del Cantar de los Cantares, ca. 1561); "al fin no se puede estar siempre en lo alto de la contemplación; de bajarse tiene" (Fray Juan de los Ángeles, Consideraciones sobre el Cantar de los Cantares, 1607).

29 El bloque II presenta igual número de subordinadas, pero sobre un conjunto mucho mayor de datos: por 5 casos en subordinadas hay 25 ejemplos en principales en el grupo I, mientras en el bloque II los 5 casos en subordinadas se oponen a 96 ejemplos en oraciones principales. 
tud del contenido deóntico (y también, como veremos, de su comportamiento sintáctico), si bien tener aparece bastante menos relacionado con la prosa jurídica y técnica (grupos IIb-c) y, en cambio, muestra frecuencias nada despreciables en el siglo XVI dentro del grupo IIIb (literatura celestinesca y teatro en prosa), dato que sugiere, junto con su presencia destacada en la novela picaresca, una distribución igualmente afín a la de querer, esto es, con inserción abundante en la interacción dialogal. ${ }^{30}$ De todos modos, tener se alinea con esos dos predicados en la preferencia clara por las tradiciones discursivas cercanas a la inmediatez comunicativa o, en todo caso, no particularmente impregnadas por los procedimientos de elaboración característicos de la prosa más elaboradamente erudita y la ficción de estilo sublime. ${ }^{31}$

30 En igual dirección apunta el hecho de que la mayoría de los ejemplos contenidos en las obras historiográficas de Ic (en concreto, 12/17 o un 71\%) se encuentren en fragmentos de discurso directo; la tendencia a asociarse con la mímesis de la conversación es, como hemos comentado, propia del tipo ICVm con querer. Valgan estos ejemplos: "y el cristiano le dijo así: Morir tengo, cuando Dios quisiere" (Gonzalo Fernández de Oviedo, Historia general y natural de las Indias, 1535-1557); "Respondiole Taríacuri: - [...] ¿Qué es esta tizne? Póntela tú. [...] Díjole Zurumban: - ¿Qué dices, señor? Ponértela tienes; yo te la pondré” (Relación de las cerimonias ... de los indios ... de Mechuacán, ca. 1541); "llorando [...] de verle ansi, le dixo: [...] rabian los bellacos de inuidia porque siruo a mi señora la virgen Maria, mas calla que no se yran con ella, pagarlo tienen" (Fray José de Sigüenza, Segunda parte de la Historia de la Orden de San Jerónimo, 1600).

31 De hecho, los escritores más cultos -en término de la época- parecen conscientes del estatuto variacional del esquema cantarlo tengo, que si encuentra cabida en el polifónico Quijote, por ejemplo, es exclusivamente en boca de Sancho (cf. 2b). 
I46 Álvaro S. Octavio de Toledo y Huerta CleCM3(1)-2016

Tabla 4. Reparto textual de los esquemas de anteposición del infinitivo al regente tener según el tipo de oración que los contiene. Siglos XVI-XVII

\begin{tabular}{lrrrrrrrrr}
\hline & Ia & Ib & Ic & IIa & IIb & IIc & IIIa & IIIb & IIIc-d \\
\hline Relativas & 3 & 0 & 1 & 2 & 1 & 0 & 0 & 0 & 1 \\
Condicionales & 0 & 0 & 0 & 1 & 0 & 0 & 1 & 0 & 0 \\
Otras Subord. & 1 & 0 & 0 & 1 & 0 & 0 & 0 & 0 & 0 \\
Total Subord. & 4 & 0 & 1 & 4 & 1 & 0 & 1 & 0 & 1 \\
Principales & 7 & 2 & 16 & 85 & 10 & 1 & 32 & 12 & 13 \\
Total & 12 & 2 & 17 & $\mathbf{8 8}$ & 11 & 1 & $\mathbf{3 3}$ & 12 & 14 \\
& $6 \%$ & $1 \%$ & $9 \%$ & $\mathbf{4 6 \%}$ & $\mathbf{6 \%}$ & $0.5 \%$ & $\mathbf{1 7 . 5 \%}$ & $6 \%$ & $8 \%$ \\
\hline
\end{tabular}

Que los esquemas con el infinitivo antepuesto a tener fueran más bien propios del diálogo informal (7a), la prédica familiar (7b) o la comunicación epistolar (7c), del refranero y la fraseología (7d) o los parlamentos cómicos en el teatro (7e), del medio manuscrito (siempre más proclive a albergar innovaciones) con preferencia sobre el impreso, no significa en absoluto que no alcanzaran, a pesar de su constante escasez, buena acogida entre varios de los más notables ingenios de la época, y particularmente del Barroco: con el importante precedente del Amadis y el Arnalte, al menos un ejemplo del fenómeno puede rastrearse en la prosa de Santa Teresa, Luis de Granada, Luis de León o Paravicino, de Mateo Alemán, Cervantes, Góngora y Quevedo, de Joan Timoneda, Vicente Espinel o María de Zayas (7f), por citar solo parte de una selecta nómina. Si resulta evidente, por tanto, que estos esquemas tuvieron arraigo en la oralidad concepcional del Siglo de Oro, no lo es menos que su vinculación con la inmediatez comunicativa implica únicamente que estaban, quizá, diafásicamente connotados, pero de ningún modo diastráticamente estig- 
matizados: en definitiva, nada indica que, aun prodigándose cum grano salis, carecieran de cierto prestigio.

(7) a. - $-[\ldots]$ Escapóseme que, si no, yo le diera la salutación [...]. -Yo os la daré a vos -dijo la vieja-; acabaros tengo antes que me acabéis (Gregorio González, El guitón Onofre, 1604)

b. Pues concluigo que este nuestro cuerpo no es parte tan apartada que more en otro barrio o persona que no nos toca, que nuestro hermano es, nuestro compańero y amigo. Sentir tenemos tantas afrentas y penitencias como nos es fuerza darle cada día, dolernos tienen sus trabajos, pesarnos sus cargas (Juan Bautista de la Concepción, $L a$ vida del justo como martirio, ca. 1610)

c. Rocío es que viene de lo alto y recebirse tiene como agua lluvia (Luis de Granada, Epistolario, 1539)

De procurar tengo se torne allá, que es mucho, para en esa tierra, haber de quien se fiar (Santa Teresa, Epistolario, "A María de San José", enero de 1580)

Suplico a vuesa merced reprenda esta sinrazón de manera que se cumpla lo que se pone, o se rompa todo, que yo comer tengo (Góngora, Epistolario, 6.4.1621)

d. Ke keramos, ke no keramos, morir tenemos (Correas, Vocabulario de refranes, 1627)

Tiene repartidas la necedad por los hombres estas infernales cláusulas: “¿Quién dijera?; no pensaba; no miré en ello [...]; yo me lo pasaré; ríase de todo; no lo crea; salir tengo con la mía; no faltará, Dios lo ha de proveer [...]" (Quevedo, La Hora de todos, 1634) 
I48 Álvaro S. Octavio de Toledo y Huerta CleCM3(1)-2016

e. Pagar tenéis el vino en alboroque / del famoso vestido que os han dado (Lope de Vega, El perro del hortelano, 1613)

¡Aparta!, / que donde se come y bebe / ir tengo, y donde se canta (Calderón, A María el corazón, 1664)

f. no han de ser todos soldados, ni todos estudiantes, oficiales y sacerdotes; que servirse tienen las gentes de las gentes (Vicente Espinel, Marcos de Obregón, 1618)

Ya estoy en este asiento: desengañar tengo a todas y guardarme de no ser engañada (María de Zayas, Desengaños amorosos, 1647)

No existen, por otra parte, indicios claros de que la construcción tuviera una adscripción dialectal concreta: en el siglo XVI la emplean el salmantino Sancho de Muñón tanto como el zaragozano Jerónimo Jiménez de Urrea, el navarro Malón de Echaide lo mismo que el vallisoletano Arce de Otálora o el valenciano Rodríguez Florián. Llama la atención, eso sí, la abundancia de ejemplos en autores nacidos al sur de los sistemas Central e Ibérico, en Castilla la Nueva y Andalucía: de un total de 57 autores que emplean estas estructuras entre 1526 y 1660, 15 (el 26\%) son andaluces, otros 12 castellanos nuevos (siete de Toledo y Ciudad Real, incluyendo a Juan Bautista de la Concepción -quien, al igual que Juan de Ávila, era nativo de Almodóvar del Campo- y otros cinco de Guadalajara o Cuenca) y 6 más madrileños, de forma que entre todos suman el 56\% (32/57) del conjunto. Con todo, dos de los escritores que mayor uso hacen de estas secuencias son un riojano (Gregorio González, el autor de El guitón Onofre, con 8 ejemplos) y un segoviano (Jerónimo Alcalá Yáñez, padre del Alonso, mozo de muchos amos, que ofrece otros 8 
casos). La vitalidad meridional de estas secuencias, pues, no parece indicadora de dialectalismo, sino que más bien apunta al carácter de innovación (pre)clásica con amplia aceptación, a pesar de su escasez, durante el Siglo de Oro, pues arraiga bien entre hablantes de territorios que, como Andalucía Occidental o el Arzobispado de Toledo, mantienen dinámicas demográficas positivas durante los dos primeros tercios del Quinientos. ${ }^{32}$

\section{TRAYECTORIA Y ESTELA DE LAS CONSTRUCCIONES}

CON INFINITIVO ANTEPUESTO A TENER

¿Cómo dar cuenta cabalmente de la génesis y evolución de cantar (lo) tengo, esa rara perífrasis fugaz - casi un bólido, por seguir el símil astronó-

32 En la acertada formulación de Pérez (1989: 12), "en el siglo XVI [...] el centro de gravedad del país se desplaza lentamente de norte a sur”. Se explica así, probablemente, la presencia de estas secuencias ya en impresos sevillanos de los albores del siglo XVI, como la Crónica sarracina (impresa por Ungut y Polono en 1499) o los pliegos sueltos del citado romance del conde Alarcos. Después del segundo tercio del siglo XVII, la anticipación del infinitivo a tener se produce ya con la perífrasis tener que + inf, y los ejemplos en prosa muestran una clara asignación dialectal al espacio lingüístico vasco, en particular a hablantes de éuscaro con un imperfecto dominio del español, como muestran los siguientes pasajes (con lo que la imitación lingüística pueda tener de más o menos burda): "hombre Juancho castigar tienes, palabras falsos" (Memorial al Presidente de Castilla, 1717); "Llevar hacemos un cañón grandísimo para el Ejército Real, y muy pronto, pues, oír tienes sus disparos" (Galdós, Zumalacárregui, 1898); “-¡Cuántos hijos hay en la casa? -iSiete, pues! -Muchos son para gente pobre. -¡Dios envía, pues! ¡Lo que te manda Dios, que coger tienes!” (Eusebio Blasco, Páginas intimas, 1885-1901); "[DON JESUSITO] -Pero lo estupendo, lo maravilloso... es ¡que no tiene novia! [SANTI] -Que elegirme tengo" (Federico Romero y Guillermo Fernández-Shaw, El caserío. Comedia lírica en tres actos, 1926). 
i 50 Álvaro S. Octavio de Toledo y Huerta CleCM3(1)-2016

mico- en que cenit y nadir prácticamente se dan la mano, por cuanto su momento de apogeo es inmediatamente previo a su desaparición? Desde luego, no puede pensarse que se trate de un esquema explicable a partir de una perífrasis con tener y el infinitivo, pues, a diferencia de lo que ocurre con el "futuro analítico" cantarlo he, falta aquí una pieza clave, aun cuando su frecuencia fuera relativamente residual: el esquema "recto" complementario con el auxiliar antepuesto al auxiliado - esto es, *(lo) tengo cantar, cf. (lo) he cantar- respecto del que cantar(lo) tengo representaría una alternativa con adelantamiento del infinitivo. ${ }^{33}$ Además, no puede ser casual que, frente a lo que ocurre con todos los esquemas análogos en que participan verbos de contenido modal (querer, deber, poder o incluso ser y haber en combinación con de y un infinitivo), con tener precedido de un infinitivo solo se documenten (como con los FCA) dos tiempos en la flexion del auxiliar, el presente y el imperfecto de indicativo, restricción morfosintáctica que, naturalmente, no afecta en absoluto

33 No parecen haber existido tampoco ni la configuración *lo cantar tengo (cf. lo cantar puedo, suficientemente documentada tras un nexo, pero *lo decir he, con un infinitivo cuya combinación con el auxiliar pospuesto no sea ambigua con el futuro "sintético": cf. la nota 15) ni la del tipo *téngolo cantar (cf. puédolo cantar y helo de cantar, pero *helo cantar), lo que muestra que cantarlo tengo comparte propiedades distribucionales con los FCA, pero no con el resto de estructuras con anteposición del infinitivo a un verbo modal. Como hemos mencionado, los dos únicos casos localizados de (lo) tengo cantar (cf. la nota 7) son algo dudosos; en cambio, secuencias formalmente equiparables a las de aparecen abundantemente cuando entre auxiliar y auxiliado interviene la preposición, condición bajo la que también es posible, claro está, que el clítico se posponga al verbo finito: "E pues la çibdat es tomada, non faze menester el rreal, ante se tiene de desfazer e el canpo quedará como de ante" (Vicente Ferrer, Sermones, 1411-1412); "y tiénese de repartir [sc. el salario del corregidor] por la Villa sola, sobre los pecheros della" (Libro de acuerdos del concejo madrileño, 1486-1492). 
a tener de + infinitivo, ni tampoco, por ejemplo, al esquema con un participio antepuesto a tener (dicho tuvo / tiene, etc.). Resulta claro, pues, que cantarlo tengo surge mediante un proceso de sustitución léxica directa de haber por tener en los FCA, del mismo modo que -como han mostrado Garachana (2011) y Garachana \& Rosemeyer (2011) - tener de + infinitivo no representa un proceso de gramaticalización autónomo, sino un reemplazo léxico a partir de la secuencia análoga y preexistente haber de + infinitivo. En este último caso, y siempre según los autores citados, la extensión de tener "progresa a través del léxico", es decir, tener va combinándose con un número cada vez mayor de predicados auxiliados, empezando por los no estativos y extendiéndose más tarde a los estativos. ${ }^{34} \mathrm{El}$ caso que aquí nos ocupa muestra un proceso distinto, pero igualmente característico de los cambios analógicos con repercusión sintáctica (cf. De Smet 2012): la "copia léxica” o "calco gramatical” (Garachana \& Rosemeyer 2001: 41) se produce con arreglo a un continuo de contextos sintácticos emparentados mediante relaciones de contigüidad formal a los que el auxiliar novedoso o sustituto va accediendo ordenada y progresivamente, es decir, asume la forma de una cadena de actualizaciones, en sentido muy próximo al de Timberlake (1977). ${ }^{35}$

34 Esta clase de extensión guiada por las propiedades aspectuales del verbo auxiliado no es en absoluto extraña en la evolución de las perífrasis del español: un proceso similar se da con la progresiva ampliación de posibilidades combinatorias de haber + participio, como ha mostrado fehacientemente Rodríguez Molina (2004), o con la progresión de estar + participio en detrimento de ser + participio (Sánchez Marco 2012).

35 Cada actualización manifiesta, en principio, "the gradual mapping out of the consequences of the reanalysis" (Timberlake 1977: 141). Puesto que se trata en este caso de un cambio analógico, motivado por la proximidad semántica de los auxiliares haber y tener, conviene 
I 52 Álvaro S. Octavio de Toledo y Huerta CleCM3(1)-2016

En un momento temprano de la competencia (y, por tanto, de la confluencia) de haber y tener, este último predicado accede a la perífrasis con de ante un infinitivo (Garachana 2011). ${ }^{36}$ Pasa cerca de un siglo, en cambio, hasta que documentamos la extensión de tener a las construcciones con un infinitivo antepuesto $(4 \mathrm{a}-\mathrm{c}, 5 \mathrm{a})$, que con haber se daban desde tiempo atrás $(3,5 b)$. Esta extensión calca las restricciones de la construcción original, pues la secuencia infinitivo + tener, al igual que su antecesora infinitivo + haber, solo aparece en subordinadas y nunca lleva, durante el siglo XV, un clítico intermedio entre auxiliado y auxiliar, manteniéndose así una neta diferenciación sintáctica entre estos esquemas y el "futuro analítico", en el que la mesoclisis es constitutiva y cuyo nicho característico son las oraciones principales. La perífrasis en que el bloque [de + infinitivo $]$ se antepone a tener puede aparecer en principales, pero es igualmente refractaria a los clíticos intermedios durante el siglo XV.

La "copia sintáctica” de los clíticos intermedios, inhibida durante cerca de otro siglo, constituye un eslabón crucial en la cadena de extensiones por la que tener va sustituyendo a haber en entornos perifrásticos, pues sitúa a estas construcciones en la órbita de los FCA, tanto más cuanto que muestran asimismo idéntico comportamiento en la restricción de la flexión temporal al presente e imperfecto. Y, en efecto, la confluencia con

sustituir en esta definición el término reanálisis por el de cambio (analógico), en la línea de las propuestas de De Smet (2013) y Fischer (2008; 2013).

36 Según Garachana \& Rosemeyer (2011: 39-40), esta sustitución se encontraba ya avanzada en el siglo XIV, de modo que "la construcción perifrástica evoluciona a un ritmo más rápido que tener como verbo transitivo", pues este predicado seguía siendo "ante todo un exponente de la posesión prototípica”. 
los FCA transformará muy rápidamente las propiedades de los esquemas con tener, a los que aquellos arrastran con gravedad incontrastable (principalmente, sin duda, en razón de su mayor masa, o sea, de su frecuencia muy superior) hacia su propia configuración formal. A partir del primer cuarto del siglo XVI, el gran crecimiento en frecuencia de cantar(lo tengo coincide, como ya hemos seńalado, con la tendencia al abandono casi absoluto de la construcción con preposición (de cantar(lo) tengo), con la preferencia muy acentuada por la aparición en oraciones principales y con la proliferación de esquemas con clítico, es decir, con el fomento, principalmente, de las secuencias cantarlo \{tengo / tenía\}, enteramente análogas a cantarlo $\{$ he / hia $\}$.

Ahora bien: los FCA experimentaron un fuerte descenso en frecuencias a lo largo del siglo XVI, sobre todo a partir de mediados de esa centuria (Figura 2). ${ }^{37}$ ¿Cómo explicar, entonces, que cantar(lo) tengo siguiera

37 Los datos de la Figura 2 proceden de un corpus de 88 obras de entre 1450 y 1660 cuyo detalle puede encontrarse en Octavio de Toledo (en prensa, a). Las cifras que se ofrecen aquí son absolutas (sobre un total de 656 casos registrados, el 88\% de ellos con el auxiliar en presente), pero el corpus fue especialmente diseñado para lograr un equilibrio aproximado tanto en número de textos como en volumen textual entre los periodos de treinta años que se representan. Al parecer, el principal competidor del FCA no fue tanto la proclisis en los entornos típicos de estas formas cuanto la solución enclítica del tipo cantarelo, como explico igualmente en Octavio de Toledo (en prensa, a): así, por ejemplo, en Lisandro y Roselia (una obra celestinesca de 1542) compiten 16 FCA (13 con flexion de presente, 3 con flexión de imperfecto) con 24 formas (22 futuros y 2 condicionales) en que el clítico sigue a una solución "sintética", de modo que la ventaja de cantarelo frente a cantarlo he es ya de 3:2 o del $60 \%$ frente al $40 \%$ de la suma de ambos esquemas; este reparto es típico para las décadas centrales del Quinientos y se ajusta asimismo a comentarios metalingüísticos como el de Juan de Valdés, que recomienda, como es sabido, ayudarate frente a ayudarte ha (Anipa 2001: 146). 
I 54 Álvaro S. Octavio de Toledo y Huerta Clecm3(1)-2016

en cambio progresando, e incluso experimentara un crecimiento importante en el último medio siglo de su existencia, entre 1600 y 1650 ? La respuesta más probable es que, desde mediados del Quinientos, cantar (lo) tengo tendió a converger con una perífrasis de contenido deóntico semejante, cantar (lo) debo. Existía para ello, una vez más, un doble apoyo formal y contextual, pues la anteposición de un infinitivo a deber se produjo característicamente en oraciones principales y seleccionaba prácticamente en exclusividad la flexión de presente o imperfecto de indicativo en el auxiliar, en contraste evidente con otras perífrasis modales, especialmente cantar (lo puedo (Tabla 5). ${ }^{38}$ Además, como muestra de nuevo la Tabla 5 y corrobora la Figura 3, los esquemas con anteposición del infinitivo a deber eran particularmente refractarios a la copresencia de la negación, una propiedad característica igualmente de los FCA y reproducida

38 Los datos de la Tabla 5 reflejan los resultados del despojo exhaustivo del CORDE para las secuencias del tipo cantarlo $\{$ debo / quiero / puedo\}, resultados que, una vez más, expongo con el detalle necesario en Octavio de Toledo (en prensa, a). Todas las cifras de la Tabla 5 son porcentuales, y están calculadas ora para los siglos XII-XVIII (Frec1), ora con exclusión de los siglos XV-XVI (Frec2), de forma que pueda apreciarse el efecto de los usos propios de estas dos últimas centurias sobre el conjunto; los dos últimos parámetros solo pueden calcularse de forma homogénea entre los siglos XII y XVI (Frec3), y las cifras que se ofrecen corresponden a ese periodo. El tipo ICVm-E es aquel en que la secuencia se halla en una oración principal, pero no en el arranque del periodo (la posición V1 o primera posición sintáctica interna a la oración). Una flecha indica semejanza entre los datos de querer y los del predicado al que dicha flecha se orienta, mientras que a falta de esta, debe interpretarse que los datos de querer asumen valores intermedios entre los de poder y los de deber. En negritas, finalmente, aparece el valor más elevado para cada parámetro. Puede observarse que, con carácter general, el comportamiento de querer es intemedio entre el de poder y el de deber, y que las estructuras con este último auxiliar se encuentran mucho más próximas al comportamiento sintáctico de los FCA. 
asimismo por cantar(lo) tengo; en las escasas ocasiones en que cantarlo debo aparecía en una subordinada, se trataba generalmente de una relativa, preferencia compartida con (de) cantar(lo) tengo (cf. la Tabla 2); y, finalmente, la configuración proclítica tras un complementante (lo cantar debo) es prácticamente inexistente (cf. *lo cantar tengo).
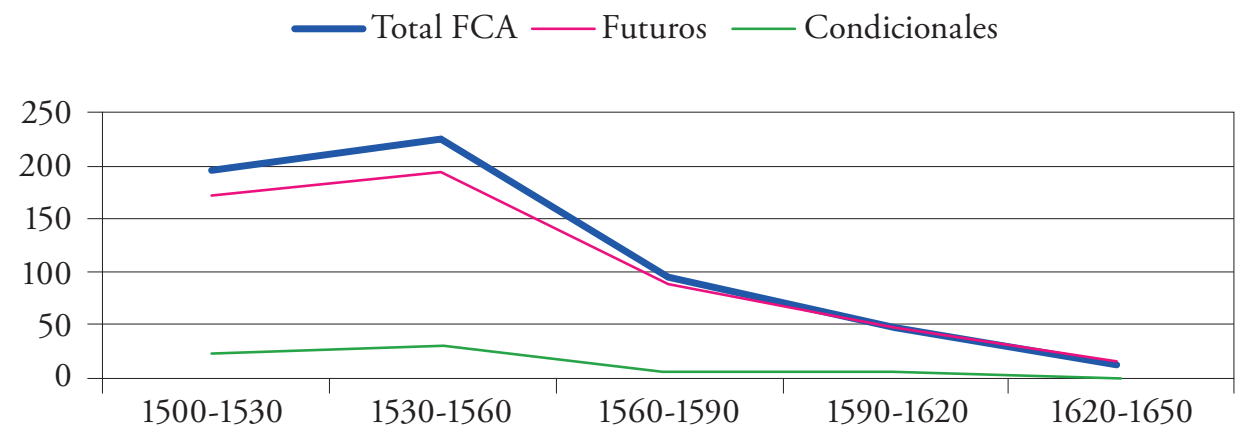

Figura 2. Descenso y pérdida del tipo FCA durante el español clásico

Tabla 5. Valores porcentuales globales para la anteposición del infinitivo acompañado de clítico (ICVm) con tres predicados modales respecto de distintos parámetros sintácticos

\begin{tabular}{|c|c|c|c|}
\hline PARÁmetro & INF + PODER & INF + QUERER & $\mathrm{INF}+D E B E R$ \\
\hline 1. Presencia en oraciones principales (Frec1) & 12 & 29 & 56 \\
\hline Presencia en oraciones principales (Frec2) & 15.5 & 41.5 & 88 \\
\hline Presencia en subordinadas: peso de las relativas (Frec1) & 54 & 55 & 75 \\
\hline Presencia del tipo ICVm-E (Frec1) & 39 & 9 & 10 \\
\hline Presencia del tipo ICVm-E (Frec2) & 5 & 0 & 0 \\
\hline Asociación con presente e imperfecto de indicativo (Frecl) & 34.5 & 44 & 79 \\
\hline Asociación con presente e imperfecto de indicativo (Frec2) & 30 & 54 & 92 \\
\hline Frecuencia de los esquemas negados (Frec3) & 46.5 & 31 & 15 \\
\hline Frecuencia del tipo CIVm (Frec3) & 10 & 12 & 5 \\
\hline
\end{tabular}


is6 Álvaro S. Octavio de Toledo y Huerta CleCM3(1)-2016

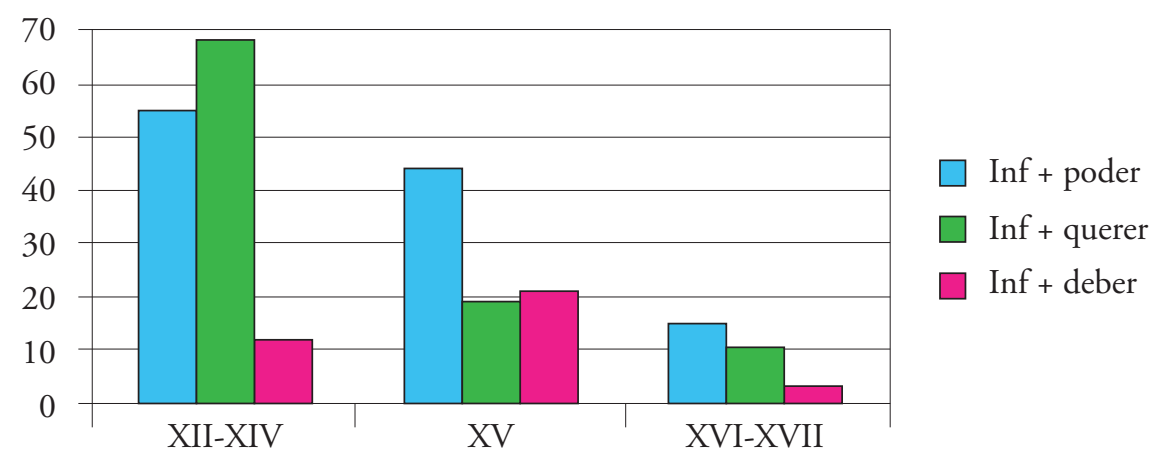

Figura 3. Porcentaje de construcciones negadas con cada verbo auxiliar en tres periodos cronológicos sucesivos

Por otro lado, cantar(lo) debo exhibía, al igual que cantar(lo) tengo, una versión productiva tanto de la construcción con clítico como del esquema sin él, a diferencia del FCA, cuya contrapartida \{cantar / decir\} he resultaba marginal: este paralelismo paradigmático pudo favorecer la convergencia de los esquemas con deber y tener. Finalmente, dicha confluencia debió apoyarse no poco en la identidad de constelaciones discursivas en que aparecían preferentemente las secuencias: como muestran las Tablas 3-4, ambas estructuras cundieron particularmente en la prosa doctrinal de carácter religioso (grupo textual IIa) y en los pasajes dialogados de las obras de ficción (grupos IIIa-b), que constituían también un ámbito textual favorecedor de los FCA, pero no, por ejemplo, de las perífrasis con anteposición del infinitivo a poder. Puesto que cantar (lo) tengo muestra asimismo una presencia importante en el grupo textual III, es posible pensar en una confluencia complementaria con las perífrasis con querer, muy presentes en dicho grupo (cf. de nuevo la Tabla 3) y que a lo largo del periodo (pre)clásico 
habían aproximado progresivamente su distribución a la de las perífrasis con deber, alejándose en cambio de los esquemas con poder (Figura 4). ${ }^{39}$

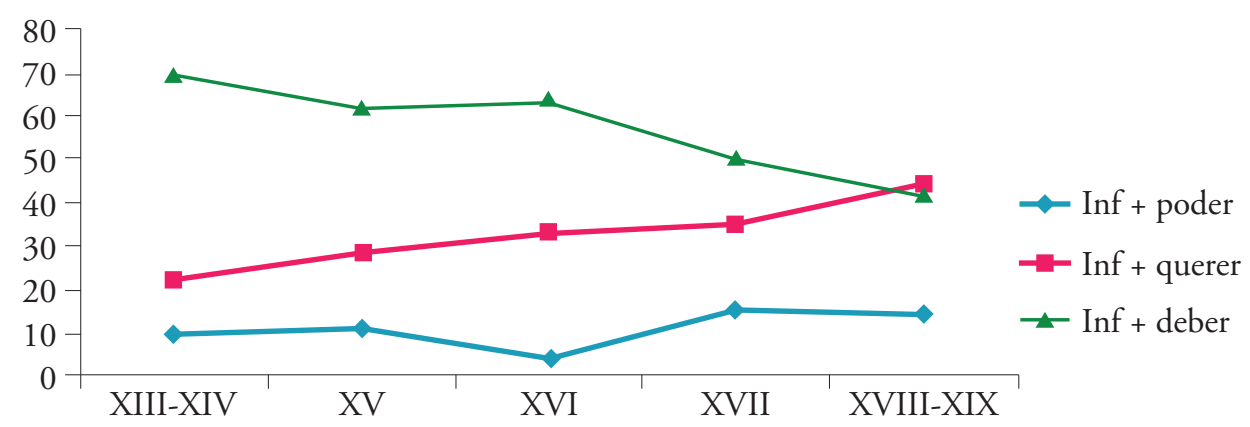

Figura 4. Contribución proporcional de cada esquema al conjunto de casos de ICVm-R para cada periodo, en \% ajustado en función de la frecuencia relativa de cada esquema en cada lapso temporal

En todo caso, la convergencia final con otros modelos perifrásticos análogos explica no solo la supervivencia y relativo éxito de los esquemas con tener durante la primera mitad del siglo XVII a pesar de la decadencia de los FCA, sino también el fin e incluso la posterior inversión de la tendencia a marginar el esquema sin clítico cantar tengo (cf. de nuevo la Figura 1), puesto que tanto cantar debo como cantar quiero coexistían

39 El entorno ICVm-R es el contrario del ICVm-E, es decir, aquel en que la secuencia ocupa el arranque o posición primera de una oración principal o, dicho de otro modo, el característico de los FCA en todo tiempo (de ahí las siglas R para "regular" y E para "excepcional"). Por lo demás, las perífrasis con querer, como muestra la Tabla 5, eran también muy poco propensas a aparecer negadas y seleccionaban con clara preferencia los tiempos presente e imperfecto de indicativo en el auxiliar. 
I 58 Álvaro S. Octavio de Toledo y Huerta CleCM3(1)-2016

armónicamente con las correspondientes construcciones mesoclíticas. En definitiva, pues, la aparición de cantarlo tengo supone un proceso de sustitución léxica, pero preludiado necesariamente por otra serie de extensiones de tener en detrimento de haber, mientras que su evolución posterior sugiere que a la atracción por parte de los FCA le sigue, en último término, un distanciamiento por aproximación analógica a otras perífrasis modales. La siguiente tabla pretende resumir la trayectoria completa de las estructuras (de) cantar (lo) tengo desde sus primeras documentaciones hacia 1425 hasta su extinción a mediados del siglo XVII.

Tabla 6. Fases del continuo sintáctico de sustitución analógica de haber por tener en las perífrasis con infinitivo (1-4) y posterior convergencia con otros esquemas modales (fase 5)

\begin{tabular}{lccccc}
\hline FASE & 1 & 2 & 3 & 4 & 5 \\
\hline Periodo & s. XIV & $1425-1490$ & $1490-1525$ & $1525-1575$ & $1575-1660$ \\
Esquema & tengo de Inf & (de) Inf tengo & (de) Inf $(\mathrm{Cl})$ tengo & Inf Cl tengo & Inf (Cl) tengo \\
Analogía con & he de Inf & (de) Inf he & de Inf Cl he + FCA & FCA & Inf (Cl) \\
& & & & $\{$ debo / quiero \\
\hline
\end{tabular}

Así las cosas, no es suficiente con mencionar el modelo de los FCA para dar cuenta de la aparición de cantarlo tengo, ni tampoco basta esta estructura para explicar la evolución ulterior del esquema. Resulta necesario ubicar la innovación cantarlo tengo en un continuo de reemplazos léxicos progresivos producidos por analogías sucesivas, y ello no solo para entender plenamente la relación que cantarlo tengo establece con el conjunto de construcciones con un infinitivo y ese mismo auxiliar (cantar tengo, de can$\operatorname{tar}(l o)$ tengo, y, en último término, tengo de cantar (lo )), sino también para 
explicar las características formales de la evolución misma. ¿Por qué, por ejemplo, la aparición de los esquemas con anteposición del infinitivo (fase 2) viene asociada ya a la selección exclusiva del presente y el imperfecto si, en cambio, la influencia de los FCA -de los que es propio este fenómeno- no es determinante hasta un momento posterior? A nuestro juicio, este hecho se explica mejor si se tiene en cuenta que la selección restrictiva de propiedades parece ser una característica de la evolución a lo largo de continuos de extensión sintáctica. Un caso que hemos analizado recientemente, el de la aparición del artículo el delante de oraciones completivas encabezadas por un complementante que (Octavio de Toledo 2014), muestra cómo, al extenderse dicho elemento a tal clase de completivas desde el entorno afín de las oraciones de infinitivo ante las que ya figuraba (el decir él eso $\rightarrow$ el que diga él eso), se producen simultáneamente otros dos cambios que suponen restricciones sintácticas firmes en la construcción emergente: por un lado, solo el artículo puede aparecer ante que, y no los demostrativos o posesivos, a diferencia de lo que ocurre en las completivas de infinitivo (cf. \{ese / tu / un\} fruncir los ojos delicadamente ${ }^{*}\{e s e$ I tu / un\} que frunzas los ojos); por otra parte, no es posible que el artículo ante que vaya precedido de una preposición, frente a lo que ocurre con los infinitivos (cf. bastará con abrir las compuertas y bastará el que abras las compuertas, pero *bastará con el que abras las compuertas). La extensión de un elemento (léxico o gramatical) a un nuevo entorno sintáctico, pues, no supone necesariamente una mera reproducción de la estructura precedente, sino que puede implicar una adaptación selectiva que impone sus propias restricciones a la nueva construcción. En el mismo sentido, parece posible que la fase 2, aun entrańando una copia léxica (tener sustituye 
i6o Álvaro S. Octavio de Toledo y Huerta CleCM3(1)-2016

a haber en un esquema al que hasta entonces no había tenido acceso), no diera lugar a una "copia idéntica" sino, más bien, a una "copia (proto)típica" que acentuó, hasta convertirlas en restricciones absolutas, tendencias preexistentes: del mismo modo que, en la época de su extensión ante que (segunda mitad del siglo XVI), el artículo era ya muy mayoritario frente a otros elementos prenominales ante las oraciones de infinitivo y estas -al menos cuando aparecían con sintagmas construidos como complementos de un verbo- no solían ir precedidas de preposiciones, las perífrasis deónticas muestran desde los orígenes, y posiblemente en razón de su misma naturaleza, un alto grado de asociación con el presente e imperfecto y no suelen aparecer negadas, ${ }^{40}$ restricciones tendenciales que el proceso de extensión transforma en reglas estructurales.

40 Para las características típicas de las oraciones de infinitivo con argumentos expresos en la segunda mitad del siglo XVI, cf. sobre todo Lapesa (1984), Mensching (1998), Meinschaefer (2008), Torres (2009) y Octavio de Toledo (2014). En cuanto a la relación de las perífrasis deónticas con la negación, debe considerarse que existe, en cualquier lengua, una asimetría semántica considerable entre la versión afirmativa y la negada de una oración cuyo verbo principal es un predicado deóntico obligativo. En una oración afirmativa, el predicado obligativo expresa la existencia de una fuerza que se impone sobre el destinatario, constriñéndolo a emprender un determinado curso de acción; cuando se niega un deóntico de esta clase, se afirma la inexistencia o la inaplicabilidad de dicha fuerza, pero no se pone en cuestión la capacidad, la voluntad o el grado de compromiso del destinatario de cara a la realización del evento. Así, una obligativa afirmativa supone un estímulo fuerte para la ejecución del evento en cuestión, mientras que la negación de la predicación obligativa representa solo un obstáculo débil, a diferencia de lo que ocurre con otros predicados modales (cf. no tengo que hacerlo, pero lo haré y ? no puedo hacerlo, pero lo haré). Dicho de otro modo, la fuerza modal deóntica de un predicado obligativo se expresa característicamente en la oración afirmativa. Al rechazar la negación, pues, los esquemas obligativos con anteposición del infinitivo se asocian a la 
Más allá de ilustrar algunos efectos típicos de los procesos de cambio sintáctico por extensión, ${ }^{41}$ asunto no excesivamente explorado hasta la fecha, el surgimiento de cantar(lo) tengo invita a reflexionar sobre las causas últimas que pueden inducir dichas extensiones a lo largo de un continuo construccional. En Octavio de Toledo (2014) hemos sugerido que la frecuencia de un esquema puede desempeñar un papel en la aparición de otros formalmente afines, ${ }^{42}$ dando así lugar a una evolución

expresión exclusiva de esta modalidad fuerte. Por otro lado, es característica de los predicados deónticos su aparición con tiempos verbales aspectualmente no delimitados, como el presente o el imperfecto, ya que la combinación con los tiempos télicos proyecta la obligación sobre un evento ya cumplido, lo que igualmente menoscaba su fuerza modal, pues la imposición de una fuerza externa es actuante principalmente en coincidencia con el origen de la enunciación en que se sitúan los interlocutores, mientras que en combinación con un pretérito, por ejemplo, la interpretación se torna preferentemente contrafactual o epistémica (cf. Juan debe hacerlo así y Juan debió hacerlo así).

41 Dichos cambios pueden ser procesos de gramaticalización en los que varía la naturaleza sintáctica de alguna de las piezas de la construcción (o de la construcción en su conjunto) o bien cambios analógicos que no alteran el valor gramatical de la construcción o sus piezas integrantes: el caso de cantar(lo) tengo es del segundo tipo, pero el de la extensión del artículo a las completivas con que es, en cambio, un ejemplo de gramaticalización, por cuanto el artículo ante que se convierte en una marca de rección (cf. Fanego 2004; Octavio de Toledo 2014) que compite con otras marcas semejantes, como las preposicionales, y las excluye: así, en "Yo me alegro el que V. m. esté desfrutando de la salud que le deseamos" (Martierena, Cartas, apud Ramírez Luengo 2013: 115), la pieza el (que de ningún modo puede ya llamarse artículo) se integra claramente en el mismo paradigma que una preposición de régimen como $d e$, exigida generalmente por alegrarse.

42 Además, el incremento en frecuencias también puede favorecer la extensión semántica a nuevos valores de un esquema que permanece formalmente inalterado, como hemos tratado de probar en Octavio de Toledo (2008) para el caso de la génesis de un valor adversativo exclusivo del nexo complejo sino es a partir del anterior valor exceptivo. En estas páginas nos 
i62 Álvaro S. Octavio de Toledo y Huerta CleCM3(1)-2016

"inducida" o "parasítica" (cf. para este ultimo término Octavio de Toledo, en prensa, b) en la que una construcción A relativamente abundante en una sincronía dada y formalmente más evolucionada (en términos de su posición relativa a lo largo de un continuo sintáctico) que otra construcción $\mathrm{B}$ diacrónicamente emparentada acaba atrayendo hacia sí a dicha construcción $\mathrm{B}$, la cual aumenta de frecuencia al tiempo que reproduce las propiedades formales y/o funcionales de A. Sin embargo, B no tiende a sustituir rápidamente o "fagocitar" (cf. de nuevo Octavio de Toledo, en prensa, b) a A, sino que mantiene frecuencias globales modestas y, por lo común, tiende a desaparecer si A entra en declive, a menos que, como parece ocurrir en el caso de cantar (lo) tengo, exista otra construcción análoga con la que pueda establecer nuevamente una relación parasítica, posiblemente con un ligero ajuste de sus propiedades (manifestado, en el ejemplo que aquí tratamos, por la tendencia a recuperar el esquema sin clítico cantar tengo, que bajo la influencia de los FCA estaba cayendo en desuso y retoma vigencia al amparo del nuevo vínculo con las perífrasis de infinitivo $+\{$ deber / querer $\}$ ). Que la frecuencia misma de un esquema pueda suscitar cambios formales en otro esquema afín es cosa que no debe sorprender si se acepta que los hablantes tienden a reproducir con mayor frecuencia aquellos esquemas a los que se encuentran expuestos más habitualmente en un momento dado, esto es, si se reconoce el papel en el cambio lingüístico de los mecanismos de replicación

ceñiremos, no obstante, a la discusión de continuos sintácticos en que pueden apreciarse alteraciones formales o combinatorias, esto es, actualizaciones sucesivas. 
o priming (cf. Jäger \& Rosenbach 2008; Mackenzie 2012 y, para el español, Sánchez Marco 2012; Octavio de Toledo, en prensa, b). ${ }^{43}$

Pero no acaban aquí las útiles enseńanzas que pueden extraerse de la observación de un cambio como el que afecta a los esquemas con el infinitivo antepuesto a tener. En un trabajo sumamente sugerente, Postma (2010) ha mostrado cómo la acción de un fenómeno emergente que no llega a asentarse (un cambio fracasado) puede no obstante resultar crucial en la activación de otra evolución afín de mayor alcance. En su corto recorrido, pues, estos cambios fugaces pueden iluminar con su estela aspectos importantes de la historia de fenómenos mucho más duraderos, conocidos y, por eso mismo, atendidos preferentemente por los estudiosos. Así, esta perífrasis con tener ofrece claves interesantes para un mejor conocimiento de su "hermana mayor", la estructura cantarlo he. En efecto, la mera posibilidad de una sustitución léxica de haber por tener en el FCA a finales del siglo XV muestra que los hablantes percibían aún en los segmentos flexionados de los FCA (incluidas las secuencias reducidas, como hemos ${ }^{44}$ o hias) auténticos auxiliares, certificando de este modo la veracidad lingüística del punto de partida del análisis gramaticográfico de Nebrija, quien argumentó precisamente con los FCA para tratar de demostrar que los futuros eran en realidad tiempos compuestos o "por rodeo" a partir del infinitivo y el auxiliar haber (cf. Girón 1997; Girón 2005). La naturaleza del FCA, por tanto, no parece haber sido, para los hablantes de fines

43 En último término, las causas generales de esta clase de cambios se relacionan, como era de esperar, con las del cambio por analogía: para el español, cf. sobre todo Elvira (2009; 2015).

44 Frente a habemos, todavía general en el castellano del ocaso medieval en cualquier entorno distinto de los FCA: cf. Bustos \& Moreno (1992) y Rodríguez Molina (2012). 
i64 Álvaro S. Octavio de Toledo y Huerta CleCM3(1)-2016

del XV y principios del XVI, sustancialmente distinta de la de cualquier otra perífrasis con anteposición del infinitivo a un auxiliar modal e intromisión del pronombre átono, como cantarlo \{tengo / debo / quiero / pue$d o\}$. La aparición de cantarlo tengo apuntala, pues, la idea de que los FCA son perífrasis, y lo singular tanto en ellos como en los esquemas mesoclíticos con otras perífrasis modales no es la posición del clítico, sino, si acaso, la del infinitivo (Octavio de Toledo, en prensa, a). Viene a reforzar esta idea el hecho de que todas las construcciones citadas experimentaron un hundimiento común en una misma época, las décadas centrales del siglo XVII. Que los FCA, que para esas fechas ya llevaban tiempo abandonándose (en favor de alternativas como cantarelo), ${ }^{45}$ desaparecieran definitivamente hacia 1660 no causa mayor dificultad, pero ¿por qué una construcción como cantar(lo) tengo, que en el siglo XVII se iba desligando del modelo en declive de cantarlo he para seguir más bien la senda de cantar(lo) \{debo / quiero\} y parecía, así, estar experimentando de nuevo un auge en frecuencias, iba a desaparecer de la noche a la mañana, precipitándose sin transición de un relativo éxito a un rotundo olvido? Sin duda, porque tanto cantar (lo) tengo como los FCA y demás perífrasis con infinitivo antepuesto se vieron arrumbadas por un cambio gramatical que las afectaba a todas por igual y, al tiempo, las sobrepasaba: la pérdida de la flexibilidad medieval, prolongada con menor intensidad duran-

45 Hubo otras estructuras que compitieron con los FCA en el Siglo de Oro. Cada vez fue más frecuente, por ejemplo, que el auxiliar haber pudiese aparecer en primera posición oracional, también con la perífrasis haber de + infinitivo, que cuando se asociaba a un clítico daba lugar a un esquema inevitablemente asociado a los FCA: "Señora, ¿̇hate de amanecer ahí? Despacio lo tomas" (Lisandro y Roselia, IV, 1, 289). 
te el periodo clásico, para situar al frente de la oración (cf. ing. fronting), es decir, en posición inicial un constituyente marcado como "foco débil" (cf. Batllori \& Hernanz, en prensa) con un valor enfático relacionado con el emisor (admiración, sorpresa, (des)aprobación, corroboración, etc.: cf. Remberger 2014), y por lo tanto intrínsecamente asociado a la asertividad y la polaridad positiva (lo que explica, naturalmente, la aversión de estas estructuras hacia la negación). ${ }^{46}$ Así, los FCA y cantar(lo) tengo desaparecen al unísono, a pesar de su distinta tendencia evolutiva durante el siglo XVII, porque la gramática del español dejó de autorizar, en las décadas centrales de ese siglo, la posición inicial del infinitivo, como la de otros elementos marcados con un foco de esa índole. He desarrollado esta argumentación con mayor detalle en otro lugar (Octavio de Toledo, en prensa, a): me importa aquí, sobre todo, subrayar que es precisamente la comparación de estas dos estructuras entre sí y con el grupo perifrástico más amplio de los verbos de contenido modal la que permite llegar a esta conclusión: la observación de los FCA en exclusiva difícilmente habría permitido formular tal hipótesis.

Finalmente, es tentador pensar que la evolución de cantar(lo) tengo podría incluso proporcionar indicios para la reconstrucción lingüística de un proceso históricamente no observable, por cuanto acontecido en algún tiempo entre el latín tardío y la aparición de los romances tem-

46 Para la marcación de los focos en la estructura informativa medieval, cf. sobre todo Fernández-Ordónez (2009), Mackenzie (2010), Sitaridou (2011; 2012), Sitaridou \& Eide (2014). Para la pérdida de las posibilidades de adelantamiento de constituyentes propias de la configuración informativa medieval en el tránsito al español clásico, cf. además Poole (2011), Rodríguez Molina (2010), Rodríguez Molina (2014), Fischer (2014), Batllori (en prensa). 
i66 Álvaro S. Octavio de Toledo y Huerta CleCM3(1)-2016

pranos que hasta ahora no nos ha sido posible establecer con precisión: la génesis y desarrollo inicial de los FCA como estructura. En las perífrasis con adelantamiento del infinitivo a querer o deber observamos una tendencia, creciente con el paso del tiempo y desconocida en el esquema "recto" con el auxiliar antepuesto, a fijar unos rasgos formales, distribucionales e incluso semánticos muy concretos: selección casi exclusiva del presente e imperfecto, preferencia muy marcada por la aparición en el arranque de las oraciones principales, rechazo de la negación. Puesto que son esos, precisamente, los rasgos más destacados de los FCA, cabe especular con la idea de que estos se forjaron de modo similar, mediante una especialización progresiva en unos rasgos a los que se inclina ya característicamente la configuración de partida (cualquier esquema con adelantamiento del infinitivo), especialización que en último término conduce al esquema hacia una distinción máximamente icónica del resto de secuencias de su propio grupo perifrástico, individualizándolo y abriendo la vía a una difusión autónoma que no es ya necesariamente solidaria con la de las otras construcciones con las que comparte el regente. En ese estadio (semejante a la fase 2 en la Tabla 6), los FCA pudieron verse atraídos analógicamente por otra construcción emparentada, la del futuro y condicional "sintéticos", bajo cuya gravitación habrían adquirido, al menos, las formas reducidas de la flexión.

No es poca, pues, la luz que la observación de una estructura tan infrecuente como cantar (lo) tengo, rápidamente corroída y disuelta por el hundimiento de la configuración gramatical que la sustentaba junto a otras de su especie, puede arrojar sobre el modo en que evolucionan las perífrasis, en particular, y cualquier fenómeno sujeto a los efectos de la analogía 
a lo largo de un continuo construccional, en un plano más general. Además de advertirnos de los peligros de invocar, tras cada cambio gramatical que tiene como resultado una modificación estructural, la presencia de un proceso de gramaticalización (no la hay, como hemos visto, en este caso), la historia de cantar (lo tengo muestra, entre otras cosas, que, al menos en la sintaxis, las relaciones analógicas no consisten meramente en vínculos abstractos de semejanza entre estructuras, sino que estas establecen mutuo contacto en el seno de constelaciones discursivas concretas, cuya identificación y rastreo constituye también una tarea irrenunciable del investigador diacrónico. Tampoco rechazará este -y menos ahora que un rápido y abundante acceso a los datos lo facilita- la oportunidad de analizar, junto a los grandes procesos evolutivos, aquellos otros cambios tenidos por triviales o insignificantes, pues, como se ve, unos y otros sostienen de consuno la delicada tela de la gramática en cualquier época dada, y por cualquiera de ellos es dable acceder a los misterios del haz de relaciones en que se insertan. 
REFERENCIAS

Fuentes $^{47}$

Alarcos = "Romance del conde Alarcos", en Romancero Viejo, ed. de Paloma Díaz-Mas, Barcelona, Crítica, 2005, pp. 282-290.

Amadis = Garci Rodríguez de Montalvo (compilador), Amadis de Gaula, ed. de Juan Manuel Cacho Blecua, Madrid, Cátedra, 1988.

Arnalte $=$ Diego de San Pedro, Tratado de amores de Arnalte y Lucenda, ed. de Yvy A. Corfis, Londres, Támesis, 1985.

Ávila, Epistolario = Juan de Ávila, Epistolario, ed. de Vicente García de Diego, Madrid, Clásicos Castellanos, 1962.

Berceo, San Millán = Gonzalo de Berceo, Vida de san Millán de la Cogolla, ed. de Brian Dutton, Madrid, Clásicos Castellanos, 1992.

Berceo, Santo Domingo = Gonzalo de Berceo, Vida de santo Domingo de Silos, en Obras completas, vol. I, ed. de Carlos Clavería y Jorge García López, Madrid, Biblioteca Castro, 2003, pp. 375-488.

$B D H=$ Biblioteca Nacional de España, Biblioteca Digital Hispánica [en línea], < bdh.bne.es>.

Biblia Medieval = Andrés Enrique Arias (dir.), Corpus Biblia Medieval, Universitat de les Illes Balears [en línea], <www.bibliamedieval.es>.

47 Los ejemplos procedentes de fuentes no recogidas en esta nómina han sido tomados directamente del Corpus Diacrónico del Español (CORDE [en línea ], <www.rae.es>) y se citan con indicación del autor, la obra y el año de composición que se les atribuye en ese corpus; en caso de discrepancia importante con la fecha del primer testimonio conservado, ofrezco detalles sobre este entre corchetes. 
Cancionero Virtual = Dorothy S. Severin (dir.), An electronic corpus of 15th century Castilian Cancionero manuscripts, University of Liverpool [en línea], <cancionerovirtual.liv.ac.uk>.

Celestina $=$ Francisco de Rojas, La Celestina, ed. de Francisco J. Lobera, Guillermo Serés, Paloma Díaz-Mas, Carlos Mota, Iñigo Ruiz Arzálluz y Francisco Rico, Barcelona, Crítica, 2000.

EE2 = Alfonso X (compilador), Estoria de España. Segunda parte [ms. de mediados del s. XIV], en Primera crónica general de España vol. II, ed. de Ramón Menéndez Pidal, Madrid, Gredos / Seminario Menéndez Pidal, 1977.

GE1 = Alfonso X (compilador), General Estoria. Primera Parte, ed. de

Pedro Sánchez-Prieto Borja, Madrid, Biblioteca Castro, 2001.

GE2 = Alfonso X (compilador), General Estoria. Segunda Parte, ed. de Belén Almeida Cabrejas, Madrid, Biblioteca Castro, 2009.

Guevara, Reloj = Antonio de Guevara, Relox de príncipes, ed. de Emilio Blanco, Madrid, CONFRES, 1994.

Guzmán = Mateo Alemán, Guzmán de Alfarache, ed. de José María Micó, Madrid, Cátedra, 1987.

Leomarte $=$ Sumas de historia troyana de Leomarte, ed. de Robert G. Black, Madison, Hispanic Serminary of Meideval Studies, 1990.

Lisandro y Roselia = Tragicomedia de Lisandro y Roselia, ed. de Rosa Navarro Durán, Madrid, Cátedra, 2009.

Lozana $=$ Francisco Delicado, La lozana andaluza, ed. de Folke Gernert y Jacques Joset, Madrid / Barcelona, Real Academia Española / Galaxia Gutenberg, 2013. 
i70 Álvaro S. Octavio de Toledo y Huerta CleCM3(1)-2016

Mejía, Silva = Pedro Mexía, Silva de varia lección, ed. de Antonio Castro, Madrid, Cátedra, 1989.

Quijote = Miguel de Cervantes, Don Quijote de la Mancha, Barcelona, Crítica / Instituto Cervantes, 1998.

Teseida $=$ trad. de Boccaccio, Teseida, ed. de Victoria Campo y Marcial Rubio Árquez, Madrid / Frankfurt, Iberoamericana / Vervuert, 1996. Valdés, Lengua = Juan de Valdés, Diálogo de la lengua [ca. 1535], ed. diplomática de Kormi Anipa, Cambridge, The Modern Humanities Research Association, 2014.

Viraldo = Libro en que se qüentan los amores de Viraldo y Florindo, aunque en diverso estilo, ed. de Luis Gómez Canseco \& Bernardo Perea Morillo, Salamanca, Universidad de Salamanca, 2003.

\section{Estudios}

Anipa, Kormi. 2000. A study of the analytic future / conditional in Golden-Age Spanish. Bulletin of Hispanic Studies 77(3). 325-338.

Anipa, Kormi. 2001. A critical examination of linguistic variation in Golden-Age Spanish. Nueva York: Peter Lang.

Batllori, Montserrat (en prensa): Haber en los futuros y condicionales analíticos. En Benito Moreno, Carlota de \& Octavio de Toledo, Álvaro (eds.), En torno a haber: construcciones, usos y variación desde el latín hasta la actualidad. Frankfurt am Main: Peter Lang.

Batllori, Monserrat \& Hernanz, María Lluïsa (en prensa). Sentential Focus and Polarity: Asymmetries between Spanish and Catalan. En Biberauer, Theresa \& Walkden, George (eds.), Syntax over time: 
lexical, morphological and information-structural interactions. Oxford: Oxford University Press.

Bourova, Viara \& Tasmowski, Liliane. 2007. La préhistoire des futurs romans: ordre des constituants et sémantique. Cahiers Chronos 19. $25-41$.

Bouzouita, Miriam. 2011. Future Constructions in Medieval Spanish: Mesoclisis Uncovered. En Kempson, Ruth M. \& Gregoromichelaki, Eleni \& Howes, Christine (eds.), The dynamics of lexical interfaces, 91-132. Stanford: CSLI Publications.

Bouzouita, Miriam. 2012. Los futuros analíticos y sintéticos en la Fazienda de Ultra Mar. En Montero, Emilio (ed.), Actas del VIII Congreso Internacional de Historia de la Lengua Española, vol. II, 1631-1642. Santiago de Compostela: Meubooks.

Bustos Gisbert, Eugenio de \& Moreno Bernal, Jesús. 1992. La asimetría hemos / habéis. En Viguera, Manuel Ariza \& Cano Aguilar, Rafael \& Mendoza Abreu, Josefa María \& Narbona, Antonio (eds.), Actas del II Congreso Internacional de Historia de la Lengua Española, vol. I, 307321. Madrid: Pabellón de España.

Bustos Tovar, José Jesús de. 2001. De la oralidad a la escritura en la transición de la Edad Media al Renacimiento: la textualización del diálogo conversacional. Criticón 81-82. 191-206.

Castillo Lluch, Mónica. 2002. Distribución de las formas analíticas y sintéticas de futuro y condicional en español medieval. En Echenique, María Teresa \& Sánchez Méndez, Juan (eds.), Actas del V Congreso Internacional de Historia de la Lengua Española, vol. I, 541-549. Madrid: Gredos. 
i72 Álvaro S. Octavio de Toledo y Huerta CleCM3(1)-2016

Chicote, Gloria. 2000. El romanticismo alemán y la construcción del romancero como objeto de estudio. En Beltrán, Rafael (ed.), Historia, reescritura y pervivencia del romancero, 17-24. Valencia: Universitat de València.

Cirot, Georges. 1911. Sur quelques archaïsmes de la conjugaison espagnole. Bulletin Hispanique 13. 82-90.

Company, Concepción. 1985. Los futuros en el español medieval. Sus orígenes y su evolución. Nueva Revista de Filología Hispánica 34. 48-107.

Company, Concepción. 2006. Tiempos de formación romance II. Los futuros y condicionales. En Company, Concepción (ed.), Sintaxis histórica de la lengua española. Primera parte: la frase verbal, vol. I, 349422. México: UNAM / Fondo de Cultura Económica.

Company, Concepción \& Medina Urrea, Alfonso. 1999. Sintaxis motivada pragmáticamente: futuros analíticos y futuros sintéticos en el español medieval. Revista de Filología Española 79. 65-100.

De Smet, Hendrik. 2012. The course of actualization. Language 88(3). 601-633.

De Smet, Hendrik. 2013. Does innovation need reanalysis?. En Coussé, Evie \& von Mengden, Ferdinand (eds.), Usage-based approaches to language change, 23-48. Ámsterdam: John Benjamins Publishing. Del Barrio de la Rosa, Florencio. 2010. El orden que XV en las oraciones de relativo del español clásico. En Dufter, Andreas \& Jacob, Daniel (eds.), Syntaxe, structure informationnelle et organisation du discours dans les langues romanes, 25-44. Frankfurt am Main: Peter Lang. 
Del Barrio, Florencio (en prensa). De tener a tener. La difusión de tener como verbo de posesión en la historia del español: Contextos y focos. En Benito Moreno, Carlota de \& Octavio de Toledo, Álvaro (eds.), En torno a haber: construcciones, usos y variación desde el latín hasta la actualidad. Frankfurt am Main: Peter Lang.

Delport, Marie-France. 2004. Deux verbes espagnols: haber et tener. París: Éditions Hispaniques.

Dryer, Matthew S. 1992. The Greenbergian word order correlations. Language 68(1). 81-138.

Dworkin, Steven. 2004. Review of Anipa, Kormi, A critical Examination of Linguistic Variation in Golden-Age Spanish. Romanische Forschungen 116(1). 90-92.

Eberenz, Rolf. 1991. Futuro analítico y futuro sintético en tres obras con rasgos coloquiales: el Corbacho, La Celestina y La lozana andaluza. En Flasche, Hans \& Körner, Karl-Hermann \& Zimerman, Günther. (eds.), Homenaje a Hans Flasche, 499-508. Sttutgart: Steiner.

Elvira, Javier. 2009. Evolución lingüistica y cambio sintáctico. Berna: Peter Lang. Elvira, Javier. 2015. Lingüistica histórica y cambio gramatical. Madrid: Síntesis.

Fanego, María Teresa. 2004. Some strategies for coding sentential subjects in English: from exaptation to grammaticalization. Studies in Language 28(2). 321-361.

Fernández-Ordóñez, Inés. 2009. Orden de palabras, tópicos y focos en la prosa alfonsí. Alcanate 6. 139-172.

Fischer, Olga. 2008. On analogy as the motivation for grammaticalization. Studies in Language 32. 336-382. 
I74 Álvaro S. Octavio de Toledo y Huerta ClECM3(1)-2016

Fischer, Olga. 2013. An inquiry into unidirectionality as a foundational element of grammaticalization: on the role played by analogy and the synchronic grammar system in processes of language change. Studies in Language 37. 515-533.

Fischer, Susann. 2014. Revisiting Stylistic Fronting in Od Spanish. En Dufter, Andreas \& Octavio de Toledo, Álvaro (eds.), Left sentence peripheries in Spanish: diachronic, variationist and comparative perspectives, 53-75. Ámsterdam: John Benjamins Publishing.

Garachana, Mar. 1997. Acerca de los condicionamientos cognitivos y lingüísticos de la sustitución de aver por tener. Verba 24. 203-235.

Garachana. Mar. 2011. Perífrasis sinónimas. ¿Gramaticalizaciones idénticas? Más retos para la teoría de la gramaticalización. En Bustos, José Jesús de \& Cano, Rafael \& Méndez, Elena (eds.), Sintaxis y análisis del discurso hablado en español: homenaje a Antonio Narbona, vol. II, 779-798. Sevilla: Universidad de Sevilla.

Garachana, Mar \& Rosemeyer, Malte. 2011. Rutinas léxicas en el cambio gramatical. El caso de las perífrasis deónticas e iterativas. Revista de Historia de la Lengua Española 6. 35-60.

García de Diego, Vicente. 1951. Gramática histórica Española. Madrid: Gredos.

García Lorenzo, Luciano. 1972. El tema del Conde Alarcos: del Romancero a Jacinto Grau. Madrid: CSIC.

Girón Alconchel, José Luis. 1997. La doctrina y el uso en los futuros en las gramáticas renacentistas. Historiographia Linguistica 24. 15-28. Girón Alconchel, José Luis. 2004. Cambios gramaticales en los Siglos 
de Oro. En Cano, Rafael (ed.), Historia de la lengua española, 859893. Barcelona: Ariel.

Girón Alconchel, José Luis. 2005. Gramaticalización y gramatización. Los futuros analíticos. En Carreter, Fernando Lázaro \& Río, Luis Santos (eds.), Palabras, norma, discurso: en memoria de Fernando Lázaro Carreter, 581-592. Salamanca: Universidad de Salamanca.

Girón Alconchel, José Luis. 2007. De nuevo sobre la gramaticalización del futuro analítico. En Delgado, Inmaculada \& Puigvert, Alicia (eds.), Ex admiratione et amicitia: homenaje a Ramón Santiago, vol. I, 563-576. Madrid: Ediciones del Orto.

Greenberg, Joseph H. 1963. Some universals of grammar with particular reference to the order of meaningful elements. En Greenberg, Joseph H. (ed.), Universals of language, 73-113. Cambridge, Massachussets: MIT Press.

Hernández Díaz, Axel. 2006. Posesión y existencia. La competencia de haber y tener y haber existencial. En Company, Concepción (ed.), Sintaxis histórica de la lengua española. Primera parte: La frase verbal, vol. 2, 1053-1160. México: UNAM / Fondo de Cultura Económica. Higashi, Alejandro. 2013. El género editorial y el Romancero. Lemir 17. 37-64.

Iglesias Recuero, Silvia. 2000. Oralidad y escritura en la Edad Media: observaciones sobre la historia de ca y que. Oralia 3. 277-296.

Jäger, Gerhard \& Rosenbach, Anette. 2008. Priming and unidirectional language change. Theoretical Linguistics 34(2). 85-113.

Kabatek, Johannes. 2005. Tradiciones discursivas y cambio lingüístico. Lexis 29. 151-177. 
i76 Álvaro S. Octavio de Toledo y Huerta CleCM3(1)-2016

Kabatek, Johannes. 2007. Las tradiciones discursivas entre conservación e innovación. Rivista di Filologia e Letterature Ispaniche 10. 331-345. Kabatek, Johannes. 2011. Diskurstraditionen und Genres. En Dessi-Schmid, Sarah \& Detges, Ulrich \& Gévaudan, Paul \& Milhatsch, Wiltrud \& Waltereit, Richard (eds.), Rahmen des Sprechens. Beiträge zu Valenztheorie, Varietätenlinguistik, Kreolistik, Kognitiver und Historischer Semantik, 89-100. Tubinga: Narr.

Kabatek, Johannes. 2012. Nuevos rumbos en la sintaxis histórica. En Montero Cartelle, Emilio (ed.), Actas del VIII Congreso Internacional de Historia de la Lengua Española, vol. I, 77-100. Santiago de Compostela: Meubook.

Keniston, Hayward. 1937. The Syntax of Castilian Prose. The Sixteenth Century. Chicago: University of Chicago Press.

Koch, Peter \& Oesterreicher, Wulf. 2011. Gesprochene Sprache in der Romania: Französisch, Italienisch, Spanisch. 2a ed. aumentada. Berlín: Walter de Gruyer.

Lapesa Melgar, Rafael. 1984. El uso de actualizadores con el infinitivo y la suboración sustantiva en español: diacronía y sentido. En Schwartz, Lia \& Lerner, Isaías (eds.), Homenaje a Ana María Barrenechea, 65-89. Madrid: Castalia.

López Serena, Araceli. 2011. La doble determinación determinación del nivel histórico en el saber expresivo. Hacia una nueva delimitación del concepto de tradición discursiva. Romanistisches Jahrbuch 62. 59-97. Lucía Megías, José Manuel. 2002. Libro del caballero Zifar. En Alvar, Carlos \& Lucía, José Manuel (eds.), Diccionario filológico de literatura medieval española, 773-780. Madrid: Castalia. 
Mackenzie, Ian. 2010. Refining the V2 hypothesis for Old Spanish. Bulletin of Hispanic Studies 87(4). 379-396.

Mackenzie, J. Lachlan. 2012. Cognitive adequacy in a dialogical Functional Discourse Grammar. Language Sciences 34. 421-432.

Meinschaefer, Judith. 2008. Nominal infinitives (and deverbal nouns) in Spanish and French. En Lahiri, Aditi \& Meinschaefer, Judith \& Schwarze, Christoph (eds.), Formal and semantic constraints in morphology, 102-17. Konstanz: Universität Konstanz.

Mensching, Guido. 1998. Infinitivo con sujeto léxico en la historia de la lengua española. En García Turza, Claudio \& González Bachiller, Fabián \& Mangado Martínez, Javier (eds.), Actas del IV Congreso Internacional de Historia de la Lengua Española, vol. I, 597-610. Logroño: Universidad de la Rioja.

Meyer-Lübke, Wilhelm. 1894 / 1899. Grammatik der Romanischen Sprachen. Formenlehre / Syntax. Leipzig: Fues.

Nieuwenhuisjen, Dorien. 2006. Cambios en la colocación de los pronombres átonos. En Company, Concepción (ed.), Sintaxis histórica de la lengua española. Primera parte: la frase verbal, vol. II, 1337-1404. México: UNAM / Fondo de Cultura Económica.

Nocentini, Alberto. 2001. La genesi del futuro e del condizionale sintetico romanzo. Zeitschrift für Romanische Philologie 117. 301-335.

Norton Frederick John \& Wilson, Edward Meryon. 1969. Two Spanish verse chap-books. Cambridge: Cambridge University Press.

Octavio de Toledo y Huerta, Álvaro. 2002. Auxiliación con ser de verbos intransitivos de movimiento (1450-1600): el caso de ir(se). Res Diachronicae 1. 257-269. 
i78 Álvaro S. Octavio de Toledo y Huerta ClecM3(1)-2016

Octavio de Toledo y Huerta, Álvaro. 2008. Un nuevo esquema adversativo en el primer español moderno (ca. 1675-1825): la historia del nexo sino es. En Moreno de Alba, José G. \& Company, Concepción (eds.), Actas del VII Congreso Internacional de Historia de la Lengua Española, vol. I, 877-907. Madrid: Arco Libros.

Octavio de Toledo y Huerta, Álvaro. 2014. Espejismo de la frecuencia creciente: gramaticalización y difusión del artículo ante oraciones sustantivas. RILCE 30(3). 916-958.

Octavio de Toledo y Huerta, Álvaro S. (en prensa, a). Futuros que se miran el ombligo: mesoclisis y anteposición de formas no personales en la historia del español. En Castillo Lluch, Mónica \& López Izquierdo, Marta (eds.), El orden de palabras en la historia del español. Madrid: Visor Libros.

Octavio de Toledo y Huerta, Álvaro S. (en prensa, b). El aprovechamiento del CORDE para el estudio sintáctico del primer español moderno (ca. 1675-1825). En Kabatek, Johannes (ed.), Akten des 3. Internationales Kolloquiums zu historischen Corpora der Iberoromanischen Sprachen. Berlín: Walter de Gruyter.

Octavio de Toledo y Huerta, Álvaro \& Pons Rodriguez, Lola. 2009. ¿Mezclando dos hablas? La imitación de la lengua medieval castellana en las novelas históricas del XIX. La Corónica 37(2). 157-183.

Pérez, Joseph. 1989. Los comuneros. Madrid: Historia16.

Pons Rodríguez, Lola. 2006. Una reflexión sobre el cambio lingüístico en el siglo XV. En Dios Luque, Juan de (ed.), Actas del V Congreso Andaluz de Lingüistica General, vol. III, 1563-1577. Granada: Granada Lingvistica. 
Pons Rodríguez, Lola (en prensa). La lengua del Cuatrocientos más allá de las Trescientas. En García Martín, José María (ed.), Actas del IX Congreso Internacional de Historia de la Lengua Española. Madrid: Iberoamericana / Vervuert.

Poole, Geoffrey. 2011. Focus and the Development of N-words in Spanish. En Berns, Janine \& Jacobs, Haike \& Scheer, Tobias (eds.), Romance Languages and Linguistic Theory 2009, 291-303. Ámsterdam: John Benjamins Publishing.

Pountain, Christopher. 1985. Copulas, verbs of possession and auxiliaries in Old Spanish: the evidence for structurally interdependent changes. Bulletin of Hispanic Studies 62. 337-355.

Postma, Gertjan. 2010. The impact of failed changes. En Breitbarth, Anne \& Lucas, Christopher \& Watts, Sheila \& Willis, David (eds.), Continuity and change in grammar, 269-302. Ámsterdam: John Benjamins Publishing.

Ramírez Luengo, José Luis. 2013. Una descripción del español de mediados del siglo XVIII. Edición y estudio de las cartas de M. Martierena del Barranco (1757-63). Lugo: Axac.

Remberger, Eva-Maria. 2014. A comparative look at focus fronting in Romance. En Dufter, Andreas \& Octavio de Toledo, Álvaro (eds.), Left sentence peripheries in Spanish: diachronic, variationist and comparative perspectives, 383-418. Ámsterdam: John Benjamins.

Rodríguez Molina, Javier. 2004. In dubio pro codice: tiempos compuestos y enmiendas editoriales en el Poema de Mio Cid. Boletín de la Real Academia Española 84(289). 131-171. 
i 80 Álvaro S. Octavio de Toledo y Huerta CleCM3(1)-2016

Rodríguez Molina, Javier. 2010. La gramaticalización de los tiempos compuestos en español antiguo: cinco cambios diacrónicos. Madrid: Universidad Autónoma de Madrid. (Tesis doctoral.)

Rodríguez Molina, Javier. 2012. La reducción fonética habemos cantado > hemos cantado en español antiguo: nuevos datos y nuevas hipótesis. En Pato, Enrique \& Rodríguez Molina, Javier (eds.), Estudios de filología y lingüistica españolas: nuevas voces en la disciplina, 167-233. Berna: Peter Lang.

Rodríguez Molina, Javier. 2014. La gramática oculta de la polaridad positiva en español antiguo. RILCE 30(3). 861-915.

Rossi, María Teresa. 1975. Formas de futuro en un romanceamiento bíblico del siglo XIII. Zeitschrift für Romanische Philologie 91. 386402.

Sánchez Marco, Cristina. 2012. Tracing the development of Spanish participial constructions: an empirical study in semantic change. Barcelona: Universitat Pompeu Fabra. (Tesis doctoral.)

Seifert, Eva. 1930. Haber y tener como expresiones de la posesión en español. Revista de Filología Española 17. 233-276 / 345-389.

Sitaridou, Ioanna. 2011. Word order and information structure in Old Spanish. Catalan Journal of Linguistics 10. 159-184.

Sitaridou, Ioanna. 2012. A comparative study of word order in Old Romance. Folia Linguistica 46(2). 553-604.

Sitaridou, Ioanna (en prensa). Unifying Long Head Movement and Stylistic Fronting in Old Spanish: Against a formal movement approach. En Castillo Lluch, Mónica \& López Izquierdo, Marta (eds.), El orden de palabras en español medieval. Madrid: Visor. 
Sitaridou, Ioanna \& Gunn Eide, Kristine. 2014. Contrastivity and information structure in the Old Ibero-Romance languages. En Bech, Kristin \& Gunn Eide, Kristine (eds.), Information Structure and Word Order in Old Germanic and Old Romance, 377-412. Ámsterdam: John Benjamins Publishing.

Stoll, Eva. 2014. Paratextos en la historiografía indiana del siglo XVI particularidades en las obras de semicultos. En Oesterreicher, Wulf \& Schmidt-Riese, Roland (eds.), Conquista y conversión: universos semióticos, textualidad y legitimación de sabers en la América colonial, 255276. Berlín: Walter de Gruyter.

Thomas, Henry (ed.). 1927. Romance del conde Alarcos. Cambridge: Cambridge University Press.

Timberlake, Alan. 1977. Reanalysis and actualization in syntactic change. En Li, Charles N. (ed.), Mechanisms of syntactic change, 141-177. Austin: University of Texas.

Torres Cacoullos, Rena. 2009. Las nominalizaciones de infinitivo. En Company, Concepción (ed.), Sintaxis histórica de la lengua española. Segunda parte: la frase verbal, vol. II, 1673-1738. México: UNAM/ Fondo de Cultura Económica.

Valesio, Paolo. 1968. The Romance synthetic future pattern and its first attestations. Lingua 20. 113-161 / 279-307.

Yllera, Alicia. 1980. Sintaxis histórica del verbo español: las perifrasis medievales. Zaragoza: Universidad de Zaragoza. 